\title{
Review of research into the concept of the microblowing technique for turbulent skin friction reduction
}

\section{Danny Hwang*}

Inlet Branch, Turbomachinery and Propulsion Systems Division, National Aeronautics and Space Administration, Glenn Research

Center, 21000 Brookpark Road, Cleveland, OH 44135, U.S.A.

\begin{abstract}
A new technology for reducing turbulent skin friction, called the Microblowing Technique (MBT), is presented. Results from proof-of-concept experiments show that this technology could potentially reduce turbulent skin friction by more than $50 \%$ of the skin friction of a solid flat plate for subsonic and supersonic flow conditions. The primary purpose of this review paper is to provide readers with information on the turbulent skin friction reduction obtained from many experiments using the MBT. Although the MBT has a penalty for obtaining the microblowing air associated with it, some combinations of the MBT with suction boundary layer control methods are an attractive alternative for a real application. Several computational simulations to understand the flow physics of the MBT are also included. More experiments and computational fluid dynamics (CFD) computations are needed for the understanding of the unsteady flow nature of the MBT and the optimization of this new technology.
\end{abstract}

Keywords: skin friction reduction, drag reduction, microblowing

\section{Nomenclature}

A area of test plate

$A R \quad$ aspect ratio, $T / D$

$C_{b} \quad$ local average blowing coefficient $\left(\frac{\rho V_{w}}{\rho U_{r e f}}\right) ;$ same as $F$

*Tel: 1-216-433-2187; fax: 1-216-977-5700

E-mail address: danny.p.hwang@nasa.gov (Danny Hwang). 
$C_{d} \quad$ drag coefficient $\left(\frac{\text { Drag }}{\frac{1}{2} \rho_{\infty} u_{\infty}^{2} A}\right)$

$C_{d 0} \quad$ total drag coefficient with solid plates

$C_{d w 0} \quad$ total drag coefficient of porous plates without blowing

$C_{f} \quad$ total skin friction coefficient, (skin friction force) $/\left(\frac{1}{2} \rho_{\infty} u_{\infty}^{2} A\right)$

$C_{f 0} \quad$ total skin friction coefficient of nonporous solid flat plate

$C_{f w 0} \quad$ total skin friction coefficient of porous plate without blowing

$C_{p} \quad\left(p_{2}-p_{1}\right) /\left(p_{0,1}-p_{1}\right)$, diffuser static pressure rise coefficient

D diameter of blowing holes, $\mathrm{mm}$

$F \quad$ blowing fraction; $\left(\rho_{b} v_{b}\right) /\left(\rho_{\infty} u_{\infty}\right)$

$T \quad$ thickness of plate, $\mathrm{mm}$

$u \quad$ velocity component parallel to surface, $\mathrm{m} / \mathrm{sec}$

$u_{\infty} \quad$ free-stream velocity

$U_{\tau} \quad$ friction velocity, $\left(\sqrt{\tau_{w} / \rho_{w}}\right)$

$U^{+} \quad u / \mathrm{U}_{\tau}$

$y \quad$ vertical distance from surface, $\mathrm{cm}$

$y^{+} \quad$ normalized distance normal to surface $\left(\rho_{w} U_{\tau} y / \mu\right)$

$\rho_{\infty} \quad$ free-stream density

$\tau \quad$ shear stress

$\mu \quad$ viscosity

\section{Subscripts}

$0 \quad$ stagnation condition/solid plate

1 diffuser inlet (throat)

2 diffuser exit

b blowing 
$\begin{array}{ll}\infty & \text { free stream } \\ w & \text { wall }\end{array}$

\section{Introduction}

Aeronautical engineers have been trying to improve the efficiency of an aircraft since the Wright Brothers' historical powered flight in 1903. The development of new propulsion systems and the improvement of aircraft design using computational fluid dynamic computer codes make it possible to fly faster, heavier, and higher. The reduction of drag is one of the areas that can contribute to the efficiency of an aircraft, and lower aircraft drag translates into such benefits as improved range, lower fuel consumption, increased payload, and reduced aircraft direct operating cost. For subsonic flow, about half of the aircraft drag is pressure drag and the other half is skin friction drag. Aircraft pressure drag has been reduced successfully by streamlining surfaces to have a desired pressure distribution. However, the reduction of skin friction drag still remains as a very challenging area of research. Many techniques and methods have been tried by many researchers for the past 20-30 years [1-19]; however, none of the techniques have been able to provide significant reduction in skin friction drag for real applications. The technology addressed in this review paper was developed specifically for reducing turbulent skin friction drag, and is called the Microblowing Technique (MBT).

One of the most promising methods for reducing skin friction is by laminar flow control. A detailed overview of laminar flow control was given by Joslin [1] in 1998. This technology has been investigated since the 1930s. Numerous wind tunnel tests and flight tests have been conducted for the past 30 years [1]. Laminar flow control has been shown to provide skin friction reduction as high as $75-80 \%$ when compared to the skin friction of a solid flat plate. [2,3]. These levels of skin friction reduction have been shown to provide significant levels of total aircraft drag reduction (1-2\%) when applied on engine nacelles $[2,4,5]$. Natural laminar flow (NLF) systems [6] maintain extended regions of laminar flow by carefully shaping the contour to extend the favorable pressure gradient further downstream. It is a passive flow control system, but the excessive pressure drag associated with NLF and the difficulty of maintaining laminar flow in a real application make this technique unusable. Hybrid laminar flow control (HLFC) systems, on the other hand, employ suction to delay boundary layer transition. The location of the suction for this method is typically in a region with very low pressure, and hence a significant amount of energy penalty is associated with applying 
suction in that region. Therefore, challenges still remain as to the cost associated with the manufacture, installation, and maintenance of suction skins and the suction bleed source. In addition, the surface quality requirements (under $0.0254 \mathrm{~mm}$ perfection) and the technology for insect and debris avoidance remain challenging tasks [25].

Another technology for reducing skin friction is the application of riblets. Riblets are an attractive method because they do not require an energy source, i.e., they are a passive boundary layer control method. They work by controlling the near-wall boundary layer flow beneath a fully turbulent boundary layer. However, a relatively small skin friction reduction of 5-15\% [7,8] cannot offset the cost associated with the initial riblet installation by the manufacturer, the maintenance and cleaning, and the reinstallion of the riblet material approximately every 5 years [9].

One of the methods that has been ignored for reducing skin friction is surface mass injection (or blowing) because many researchers believed that the penalty associated with blowing was very large because of the possibility of causing flow separation. Despite this shortcoming, many experiments were conducted in the 1970s for a flat plate with no pressure gradient [10-19]. It was well established that blowing did significantly reduce skin friction with respect to the skin friction of the porous plate without blowing. However, it will be shown later in this paper that the skin friction of these conventional porous plates suffered from the problem of large effective roughness. These plates have a large skin friction when compared to the skin friction of a solid flat plate; in some cases, on the order of a factor of 2 or more. Because of this large amount of "no blowing" skin friction, it was impractical to reduce skin friction by blowing for these plates because it required a very large amount of blowing air (which blows away the boundary layer) to reduce the skin friction below that of a solid flat plate value.

The subject of this paper is the innovative skin friction reduction method called the MBT $[20,23]$. The MBT has been developed through tests conducted since 1995 in the Advanced Nozzle and Engine Components Test Facility [21] at the NASA Glenn Research Center. In this method, an extremely small amount of air is blown vertically at the surface through specially designed microholes with high aspect ratio. This reduces the surface roughness and the gradient of the flow velocity profiles on the surface thereby reducing skin friction. 
The method has been proven to achieve over $50 \%$ reduction in skin friction for a wide range of subsonic and supersonic flow conditions. Results of the experiments, as well as CFD results designed to help understand the underlying flow physics of the MBT, are presented in this review paper.

\section{Evaluation of Concept}

\subsection{Evaluation of concept with experiments}

The idea of the MBT was conceived from CFD computations conducted in 1993 by the author. Because of the difficulty of using CFD to adequately evaluate the concept, funding was applied for evaluating the concept experimentally. The NASA Glenn Director's Discretionary Fund (DDF) awarded a project for evaluation of the MBT for 3 years beginning in 1995. Other NASA Glenn projects (Green Engine Project, Supersonic Quiet Engine program and the Propulsion Base Program) subsequently funded the research of the MBT until 2002. The Advanced Nozzle and Engine Components Test Facility, CE22 [21], was chosen to be the test facility for conducting experiments to evaluate the MBT concept. The facility was originally designed for testing nozzles, so it was modified to have several different small wind tunnels to replace the usual test nozzle. The facility can provide a total pressure as high as 2.7 atmospheres and the exhaust pressure at the exit of the wind tunnel can be adjusted from 1 atmosphere to near vacuum. This arrangement can provide different Reynolds numbers for a wide range of flow conditions. The porous test plates (skins) having a size of 12.36 by $25.06 \mathrm{~cm}$ were interchangeable for all experiments. As mentioned earlier, the porous plate for the MBT should have low effective roughness such that the unblown skin friction (the skin friction of a porous plate without blowing) should be as close to the skin friction of a solid plate as possible. Because of this, attention was focused on looking for right plates for the MBT. Without any prior knowledge of the MBT, the design of a plate, which is porous but with low unblown skin friction (low effective roughness), was a challenging task. The first test plate was designed and manufactured in 1995 with a microhole diameter of $0.165 \mathrm{~mm}$, a plate thickness of $1.02 \mathrm{~mm}$, and a porosity (percentage of open area) of $23 \%$. A schematic figure of this test plate is shown in Fig. 1 and the shape of the laser-drilled holes is shown in Fig. 2. It can be seen from Fig. 2 that the shape of the laser-drilled holes is very irregular. In spite of these irregular holes, it turns out that this porous plate was one of the best MBT plates and was used for many subsequent experiments.

Fig. 3 shows the force balance used for the early stage of experiments. It was loaned to NASA Glenn by the Naval Surface Weapons Center. Its linear variable differential transformer (LVDT) was replaced by a load 
cell with a maximum load capability of $500 \mathrm{~g}$. The accuracy of the load cell was $+l-0.25 \%$. During the later stage of experiments, a new two-component force balance was built as shown in Fig. 4. A load cell with a maximum load capability of $11340 \mathrm{~g}$ was installed in this balance with an accuracy of $+/-0.025 \%$. The new balance was designed such that it could be interchanged with the old balance. The balances were placed under the test section inside a sealed compartment to minimize air leakage through the gap between the plate and the tunnel floor.

\subsubsection{Flat plate test in subsonic flow (1995-1996 [23])}

The first wind tunnel built for the test facility was a simple rectangular duct with a constant cross section (20.32 $\mathrm{cm}$ wide, $14.2 \mathrm{~cm}$ high, and $63.5 \mathrm{~cm}$ long) as shown in Fig. 5 . The tunnel was expected to provide a constant pressure gradient in the test section such that no pressure force acted on the balance during the tests. A $12.7-\mathrm{cm}$-long transition duct was used to connect the duct to the facility. With this arrangement, the facility provided stable Mach numbers from 0.3 to 0.7 with an exhaust pressure of 0.24 atmosphere the pressure at an altitude of $10.7 \mathrm{~km}$ ). The test plate was placed on the top of the balance and flush with the tunnel floor. There was a gap of less than $0.2 \mathrm{~mm}$ between the test plate and the tunnel floor. In order to distribute the blowing air evenly, a 30-micron-high-density polyethylene plate with a thickness of $9.14 \mathrm{~mm}$ was used for the inner layer as shown in Fig. 1. The gap between the inner layer and the outer layer was about $0.8 \mathrm{~mm}$.

The skin friction measured by the balance was the average skin friction of the entire test plate. Seven porous test plates as listed in Table I were tested. The plates designed as the NASA series, PN2 and PN3 were laser drilled, while the GAC series plates were provided by Northrop Grumman and were manufactured with a proprietary procedure. The GAC series porous plates were originally made as face sheets for acoustic liners.

The skin friction of a solid flat plate was first determined to find the reference value of skin friction and then the skin friction of the various porous plates was measured without blowing and compared with the reference value as shown in Fig. 6 . The ratio of skin frictions between the porous plate without blowing and the solid flat plate is called the unblown skin friction ratio. If the unblown skin friction ratio is equal to 1 , then the skin friction of the porous plate is the same as the skin friction of the solid plate. The porous plates with an unblown skin friction ratio of less than 1.2 were determined to be the most promising and were called the MBT skins. It was felt that because of their low unblown skin friction, these plates provided the best chance 
for success of the MBT. Three plates (PN2, PN3, and GAC1897) were identified as the MBT skins. An important finding from this test was that the plates with small microholes were not necessarily able to provide the lowest effective roughness. The controlling parameter actually was the aspect ratio of the holes, the ratio of plate thickness with respect to the diameter of the hole, as indicated in Fig. 6. The aspect ratios of the PN2, PN3, and GAC1897 skins were all over 4. The aspect ratios of the other porous plates were all less than 2. The unblown skin friction ratios of these plates (GAC2002-2005) were so high (1.5 or more) that with microblowing, it was impossible to get the skin friction below the value of a solid flat plate. The microporous plates, PN2 and GAC1897, which had the highest hole aspect ratios of 6.2 and 5.1 respectively, were used for many subsequent MBT tests.

Typical skin friction reduction results from this test are shown in Fig. 7 for the PN2 skin. The reduction in skin friction of PN2 is as high as $60 \%$ (i.e., $C_{f} / C_{f 0}=0.4$ ) with the highest blowing rate of $0.205 \mathrm{~kg} / \mathrm{m}^{2} / \mathrm{sec}$ at a Mach number of 0.3 while the maximum reduction is $30 \%$ at a Mach number of 0.7 . This difference was originally thought to be due to a Reynolds number effect [23]. After supersonic tests were conducted in which the skin friction reduction was even more than $80 \%$, the data of these subsonic tests were revisited and the real reason was found for why the reduction was less for Mach 0.7 than for Mach 0.3. Figure 8 shows the static pressure distribution along the wind tunnel wall for the Mach 0.3 and 0.7 cases. At Mach 0.3, the static pressure over the test plate was a constant, therefore the static pressure at the leading edge of the test plate was equal to that at the trailing edge. As mentioned earlier, there was a gap between the test plate and the tunnel floor. Because of the constant axial static pressure in the test section at Mach 0.3, the pressure in the sealed chamber of the balance is also a constant at this Mach number and should not introduce any erroneous force measurement. However, at a Mach number of 0.7 , the static pressure at the trailing edge of the test plate is lower than that at the leading edge due to the boundary layer buildup within the test section as shown in Fig. 8. The resulting unbalanced force inside the balance chamber caused an erroneous measurement of skin friction. The measured skin friction actually was higher than the real value and that is why the reduction of skin friction is lower at a Mach number of 0.7 (Fig. 7). A correction has not actually been done for those data, however, the reduction of skin friction at a Mach number of 0.7 is expected to be as high as the case for a Mach number of 0.3 , i.e., $60 \%$ for PN2. The skin friction ratios for all three MBT skins are shown in Fig. 9 at a Mach number of 0.3 . The figure shows that different degrees of skin friction reduction were achieved with 
the three different MBT skins that were tested. The question becomes, "What parameters affect the effectiveness of the MBT to cause such a difference?" The answer will be given in Section 2.1.6.

\subsubsection{Evaluation of pressure drag penalty (1996 [24])}

As mentioned earlier, the total drag of a subsonic aircraft consists of two types, one is skin friction drag and the other is pressure drag. In order to understand the effect of the reduction in skin friction on the total drag, a second MBT test was conducted in 1996. The wind tunnel was modified such that a constant thickness airfoil ( $2.03 \mathrm{~cm}$ thick, $13.7 \mathrm{~cm}$ high, and $45.72 \mathrm{~cm}$ long) installed on the tunnel floor and was mounted on a balance with a gap of less than $0.2 \mathrm{~mm}$ as shown in Fig. 10. A photograph of the experimental setup is shown in Fig. 11. Rectangular porous plates having dimensions of 12.36 by $25.06 \mathrm{~cm}$ were installed on both sides of the flat section of the airfoil, $5.08 \mathrm{~cm}$ from the leading edge (Fig. 10). The plate size is identical to the plates used in all other MBT experiments. The inner layer material had a thickness of $3.175 \mathrm{~mm}$ and was a 30-micron, high-density, polyethylene porous plate, which was glued to the outer layer around the edge of the plate, that is, there was no gap between the outer layer and inner layer. Twelve porous plates were tested in this experiment as listed in Table II.

A reference total drag using solid flat plates was first measured for various Mach numbers. The total drag for various porous plates was then measured without blowing and with various blowing flow rates. Results are shown in Figs. 12 and 13. Figure 12 shows that the GAC1897 plate achieved a total drag reduction of $2.2 \%$ below a solid flat plate total drag value at a Mach number of $0.35\left(\mathrm{Re} / \mathrm{m}=1.96 \times 10^{6}\right)$. This is a significant finding. Even though the MBT results in a higher penalty of higher pressure drag for higher blowing rates, it is possible to reduce the total drag if the blowing rate stays low (microblowing). Another important point that was not discussed in [24] is that the skin friction measurement in this test is lower than the real value. This is a result of the blockage caused by the blowing which increased the velocity of the free-stream flow and made the surface pressure near the trailing edge lower. The report [24] did not take this into consideration; therefore, the real total drag reduction could be greater than $2.2 \%$.

In order to determine drag characteristics of porous plates, the unblown drag ratio, which is defined as the ratio of porous plates without blowing $\left(C_{d w 0}\right)$ to total drag with a solid plate $\left(C_{d 0}\right)$, was presented with respect to Reynolds number per meter. Only two among the 12 porous plates tested were considered as MBT skin 
candidates. However, with microblowing, the LARC1 plate was not able to achieve a drag reduction because the porosity of the plate is only $1.1 \%$ (not enough holes to achieve the effectiveness of the MBT). Hence, porosity was determined to be another very important parameter of the MBT as demonstrated by this test.

\subsubsection{Drag reduction on a large-scale nacelle (1997 [25,26])}

After successful small-scale tests at NASA Glenn, an experimental study was carried out to evaluate the microblowing turbulent drag reduction concept on a $76.2-\mathrm{cm}$-diameter aircraft engine nacelle. This experiment was funded by NASA Glenn, as part of the Large Engine Technology (LET) Program.

The test model was originally designed for a hybrid laminar flow control (LFC) experiment sponsored by NASA Langley. Since the LFC experiment used one of the MBT skins (GAC1897), a slight modification of the air suction system was sufficient to provide a uniform amount of blowing air for an evaluation of the MBT. After back-to-back experiments of the LFC test and the MBT test on the same nacelle, the following assessment of comparison was indicated [25]: "LFC is operationally complicated in that the process is highly sensitive to surface quality. Small (on the order of $0.0254 \mathrm{~mm}$ ) imperfections in the nacelle surface can render LFC difficult or impossible to accomplish. An attractive element of microblowing is that it achieves drag reduction beneath fully developed turbulent boundary layers. Thus, surface quality is not an issue and operationally this drag reduction method may be easier to implement on flight vehicle systems."

The test was conducted in the Acoustic Research Tunnel (ART) at United Technologies Research Center (UTRC ). The test model is shown in Fig. 14. The test skin of GAC1897 (listed in Table I) with a size of 91.44 by $91.44 \mathrm{~cm}$ can be seen clearly in the figure. The blowing plenum assembly with six chambers was located under the skin to provide uniform microblowing air. No attempt was made to vary the flow rate of each individual chamber. In this experiment, the calculation of nacelle drag was based on hot wire surveys of the turbulent boundary layer. The measurements were made at three locations: at the leading edge, at the middle, and at the end of the test plate (Fig. 15). The surface static pressure distributions on the nacelle were controlled by carefully designing the contours of the test section wall. Contours were designed to provide either a nominal zero pressure gradient, a mild adverse pressure gradient, or a strong adverse pressure gradient as shown in Fig. 15 for the cruise unit Reynolds number case of $6.3 \times 10^{6}\left(\mathrm{~m}^{-1}\right)$ (corresponding to operation at the cruise conditions of 0.8 Mach number at an altitude of $10.7 \mathrm{~km}$ ). A control volume analysis 
was used to calculate the average drag between two measuring stations $[25,26]$. Note that all skin friction and total drag measurements conducted at NASA were the direct measurement by using a force balance.

Test results are shown in Figs. 16-18 for the zero pressure gradient, the mild adverse pressure gradient, and the strong pressure gradient cases, respectively. For each case, test results are presented for the upstream panel region (between the upstream measuring station and the midpoint measuring station), the total panel region (between the upstream measuring station and the downstream measuring station), and the downstream panel region (between the midpoint measuring station and the downstream measuring station). For all the pressure gradient cases the skin friction reduction was limited in the upstream panel region while significant reduction (50\% or more) was shown in the downstream panel region. Since the blowing flow rate was uniform for all regions during this test, no attempt was made to optimize the blowing flow rate in each individual chamber to achieve a maximum skin friction reduction. However, some effort to find a scaling parameter is described in $[25,26]$. Anyway, the degree of skin friction reduction in the downstream region, $50 \%$ or more, is consistent with the previous flat plate test results.

\subsubsection{Flat plate test in supersonic flow (2000-2001[27])}

In order to evaluate the skin friction reduction in supersonic flow, a specially designed supersonic wind tunnel was manufactured at NASA Glenn for the CE22 Test Facility [21]. It was designed such that there was no shock in the wind tunnel and the Mach number in the test section was designed for 2.0 , although it turned out that the Mach number in the test section was 1.9 due to the boundary layer buildup. The dimensions of the test section were 10.8 by $20.32 \mathrm{~cm}$. The $12.36-$ by $25.06-\mathrm{cm}$ test plates (same size as the other MBT tests) and were installed flush to the tunnel floor, at an axial position of $76.2 \mathrm{~cm}$ downstream of the beginning of the supersonic duct as shown in Fig. 19. There was a small gap of less than $0.18 \mathrm{~mm}$ around the test plates. A fairly constant pressure gradient region in the test section was achieved without a shock in the duct as shown in Fig. 20. Seven porous plates were selected for testing as shown in Table III. The test plates PN23 and GAC1897 were known to work for subsonic flow, and several slanted angle holes test plates with either staggered or aligned hole patterns [27] were built and tested as indicated in Table III. The GAC2054 test plate, which had a low unblown skin friction but did not work for subsonic flow was included in the supersonic flow test. Because it had a mirror-smooth surface on the porous plate, it was thought that it might 
have good performance in supersonic flow. Northrop Grumman provided both the GAC1897 and the GAC2054 plates.

The skin friction ratios of the various porous plates are shown in Fig. 21. The results were very surprising in that a skin friction reduction of $80 \%$ or more was achieved in supersonic flow for all the test plates except GAC2054. The reason why GAC 2054 did not reduce skin friction is that the porosity of GAC2054 is only $4 \%$ and only a small area of the porous plate was affected by the microblowing air. Therefore, porosity is definitely another parameter affecting the performance of the MBT. From this experiment, it was also found that the inclination and alignment of holes did not seem important. It was concluded after this test that the MBT can be applied to many types of flows: turbulent or laminar, subsonic or supersonic.

\subsubsection{Effectiveness of MBT in adverse pressure gradients (1999-2001[28])}

Up to this point, the experiments had been done for only zero pressure gradient cases except the test done with the nacelle at UTRC in 1997. An appropriate question to ask is, "Is the MBT as effective in a very strong adverse pressure gradient that might be encountered in a compressor?" To answer this question, an experiment to investigate the effect of adverse pressure gradients was started in 1999. The wind tunnel described in Section 2.1.2 was modified for this experiment. The sidewall was modified to provide a diffuser static pressure rise coefficient $C_{p}$, measured from throat to exit, of approximately 0.6 , which is a typical value for a compressor. A schematic top view of the wind tunnel is shown in Fig. 22. The test model was mounted on the top of a force balance with a small gap separating the test model and the tunnel floor (the same setup as in Section 2.1.2). Since the flow is in the adverse pressure gradient region, the tare force to account for pressure loading on the balance was carefully accounted for in data analysis [28]. The force measurement from the balance for this case includes pressure drag and skin friction drag. A method was developed to separate the skin friction drag from the total drag and is described in [28]. In order to be consistent with previous results, Fig. 6 of [28] for the PN23 porous plate was replotted and is shown in Fig. 23. Only the data for Mach 0.4 and 0.7 are shown in Fig. 23. For this experiment, the tests were repeated many times and the linear mean square fits to all the data are shown in the figure. As can be seen from this figure, disparity in force balance measurements was as large as $20 \%$ at the low Mach number. However, based on the linear mean square lines, the identical skin friction reduction of $50 \%$ was achieved in this adverse pressure gradient 
as was achieved in a zero pressure gradient (Fig. 7). It should be noted that the 30-micron polyethylene porous plate was placed under the PN23 porous plate for these results. This was done after it was discovered that the flow could separate without the polyethylene porous plate due to recirculation of the blowing air (i.e., at the higher surface pressure region close to the trailing edge, the air flows into the porous plate (microsuction) and it flows back out with microblowing air into the free stream somewhere upstream). Various inner porous plates were tested; however, enough testing could not be done to provide meaningful results on the proper selection of an inner porous plate design.

As the microblowing flow rate was increased, a less than $1 \%$ reduction in the downstream total pressure was measured at the location shown in Fig. $22(x=83.82 \mathrm{~cm})$, as reported in [28]. Considering the scatter of measured values (Fig. 23) and the unsteadiness of the flow, further tests are needed to measure more accurately this downstream total pressure. Since the test section is very small, the effect of the MBT on the tunnel wall boundary layers should also be included in these future tests.

\subsubsection{Parametric study of microhole plates (2001-2002 [29])}

Up to this point, many experiments had been conducted that indicated that the hole angle, pattern, diameter, aspect ratio, and porosity were all parameters that affected the efficiency of the MBT skins. With so many parameters, it is impossible, even with design-of-experiments techniques, to optimize the MBT skins. In order to solve this problem, a sensitivity study was first performed and from those experiments, it was concluded that the additional effort to angle and stagger the holes was unwarranted in terms of the skin friction benefit $[27,29]$. The impact of the remaining three parameters was evaluated by fixing two parameters at the reference values while varying the third parameter so that a guideline for selecting porous plates for the MBT can be provided.

Table IV lists the specification of the porous plates tested. PN23 was chosen as the reference plate for this experiment.

The impact of varying hole diameter is shown in Fig. 24. The results clearly show that the minimum skin friction ratio was at the hole diameter Reynolds number of 400 (corresponding to a diameter of $0.1651 \mathrm{~mm}$ ). For plates with larger holes, it is postulated that in the zero blowing limit, the boundary layer flow enters the microhole and stagnates and, thus, causes a large effective plate "roughness." For plates with smaller holes, 
not only are a large number of holes required (which might even be impractical), but also the effective roughness is higher from the measured experimental data (Fig. 24 with $F=0$ ).

The impact of hole aspect ratio (ratio of plate thickness to hole diameter) is shown in Fig. 25. For plates with low aspect ratio, it is postulated that, in the zero blowing limit $(F=0)$, the boundary layer flow penetrates deeply into the microhole and gives rise to large effective plate roughness. For plates with higher aspect ratio, it is postulated that the boundary layer flow cannot penetrate too deeply into the microhole due to the vortices formed inside the hole (similar to the open cavity flow). From this experiment, the best aspect ratio for the MBT was about 6.

The impact of porosity (percent of open area) is shown in Fig. 26. Why the skin friction is much higher at a porosity of $33 \%$ is unknown. For a fixed hole size, the number of microholes is directly proportional to the plate porosity. The skin friction ratio generally increases weakly with increasing porosity (and number of microholes). The skin friction reductions at 13 and $23 \%$ porosity were about the same. Unfortunately, test plates with less than $13 \%$ porosity were not built for this test. The skin friction of a plate with less than $13 \%$ could be either higher or lower than that of a $13 \%$ plate. For a real-world application, fewer holes means lower manufacturing cost and therefore design trades will involve optimization of hole size and porosity to minimize hole number while maximizing skin friction reduction. For the $0.17-\mathrm{mm}$ holes considered here, the best porosity is estimated to be about $15 \%$ or less.

\subsection{Understanding of flow physics with CFD}

\subsubsection{Numerical analysis using CFL3D (1998 [22])}

The first CFD study on the MBT was done by Prof. Shih and his student, Lin [22], in 1998. The computational domain they considered is the region bounded by the broken lines shown in Fig. 27. As can be seen from this figure, only four half holes were simulated because of the symmetry in the spanwise direction and the need to limit the computational CPU time. The computational cost is further reduced by applying only half thickness of the incoming boundary layer as the inflow boundary condition. Keep in mind that the experiments done at NASA were for a plate size of 12.3 by $25.05 \mathrm{~cm}$ with $0.165-\mathrm{mm}$ microholes with the total number of holes exceeding 400000 . For this computational study, only four holes are simulated. Also, 
the plenum in the NASA experiment [23] is not simulated in the computation in order to ensure an identical flow rate through each of the microholes.

The computation was conducted using a cell-centered finite-volume code called CFL3D [30,31]. A low Reynolds number $\kappa-\omega / S S T$ turbulence model was used. The authors of this paper pointed out the following:

First, only steady-state solutions were investigated. Second, the turbulent model has not been modified for effects of microblowing, and third, only the mean quantities will be used to obtain an understanding of the nature of the microblowing flow field. The overlapping structured grid system used in this study is shown in Fig. 28. The total number of grid points is 1.284 million and it takes 10 hours of CPU time on a Cray YMP computer to complete a calculation.

The complicated flow associated with microblowing is shown in Fig. 29, indicating velocity flow field and streamlines for three blowing fractions: $0,0.0015$, and 0.015 ( $M$ is the blowing fraction in Figs. 29-31). The figure shows that the boundary layer flow can enter and exit each hole. It also can penetrate up to twice the hole diameter into it before exiting again in the form of very complex vortical structure and finally, it is noted that the vortical structure may be unsteady and cannot be assessed in this steady-state computational study.

Figure 30 shows the spanwise-averaged normalized shear stress with holes included and Fig. 31 with holes excluded. Keep in mind that only four rows of microholes were simulated in the calculation whereas the skin friction of NASA's experiment was the average skin friction on a $12.36-$ by $25.05-\mathrm{cm}$ plate including thousands of holes. Even with only four rows of holes, the figures show that the skin friction is decreased in the streamwise direction and the reduction in the skin friction is larger for a larger blowing flow rate. These findings are consistent with NASA's experiments. The authors of this paper [22] indicated that with only four rows, the asymptotic value of the drag reduction has not been reached. Assuming a linear drop, an asymptotic value of $75 \%$ could be reached with 13 more rows for the case of a blowing fraction of 0.0015 .

Using the limitations of existing computers, this study indicated how difficult it is to model all the microholes to simulate microblowing. And since microblowing is a highly unsteady flow, the task to simulate unsteady microblowing would be even more difficult.

\subsubsection{Large eddy/lattice Boltzmann simulation (2002-2004 [32-34])}


The large eddy/lattice Boltzmann simulation for microblowing was conducted by Prof. Menon and his student, Feiz, at the Georgia Institute of Technology from 2002 to 2004.

Three-dimensional large-eddy simulations (LES) of multiple jets in crossflow were conducted using the 19-bit lattice Boltzmann equation (LBE) method coupled with a conventional finite-volume (FV) scheme. In this coupled LBE-FV approach, the LBE-LES is employed to simulate the flow inside the jet nozzles while the FV-LES is used to simulate the crossflow. Since the Boltzmann equation is a single scalar equation, it is computationally very efficient. This approach takes the best of both worlds and couples them together within a single formulation.

The LBE-LES method was first used to simulate a single jet in crossflow [35] and had very good agreement with experimental data. The LBE-FV approach was then applied to a limited set of holes, that is, 3 by 3 square pattern of injection holes with $D=0.5 \mathrm{~mm}$ and equally spaced a distance of $D$ apart, as shown in Fig. 32. From the NASA experiment, it was known that the irregular hole shape of laser-drilled holes can reduce the skin friction by the same magnitude as the circular holes. It was known that the square hole shape of this study would provide a meaningful result. Turbulent inflow profiles were specified 5 diameters upstream of the injection holes with a free-stream velocity of $U_{0}=138.54 \mathrm{~m} / \mathrm{s}$ and a boundary layer thickness of $\delta=12 \mathrm{~mm}$. The locations of these boundary conditions are indicated in Fig. 32. The plate porosity (percentage of open area) is $25 \%$ and three bowing rates of $0.02,0.07$, and 0.003 were simulated. The holes have an aspect ratio $(T / D)$ of 4 . Figure 33 shows the comparison of the experiment profile at the inflow with the assumed inflow profile. The figure also shows the velocity profile at the injection port. As expected, the friction velocity goes down due to injection and higher $U^{+}$is achieved. Figure 34 shows the skin friction ratio at three blowing flow rates. As in the experiments, the skin friction is lower for the larger blowing flow rates. Despite the fact that only nine holes were simulated in this study, the trend of skin friction reduction relating to the blowing flow rate is similar to the results obtained with CFL3D.

Analysis from this research also shows that the interaction between blowing flow and the boundary layer is limited to a region up to $y^{+}=19$ [34]. This is similar to the conclusion from the experiments $[25,26]$ that the blowing flow penetrates the boundary layer out to an upper limit near $y^{+}=15$.

The results from this research also suggest that the wake effect of the leading hole can change the local pressure above the holes behind it and can cause periodic reduction of the mass flow. This means that the 
interaction between the blowing flow and the boundary layer is very unsteady. To really understand the flow physics of the interaction between blowing flow and the boundary layer, an unsteady CFD calculation is needed.

As mentioned in [34], the MBT suppresses the near-wall vortices and modifies the near-wall sweep-burst events. This in turn reduces the skin friction drag.

\section{Issue and Discussion}

Many experiments have been conducted at NASA as well as one test at United Technologies Research Center to assess a new technology for turbulent skin friction reduction called MBT. All experimental results consistently show that the MBT can reduce the turbulent skin friction more than $50 \%$ in subsonic flow and more than $80 \%$ in supersonic flow. So far, the tests have been conducted in a very small wind tunnel in which the boundary layer buildup caused erroneous measurements of skin friction. For further evaluation of this new technology, experiments in a large wind tunnel are needed. The application of the MBT for supersonic aircraft could be more beneficial because of readily available low surface pressure (fewer penalties for providing microblowing air) and more uniform surface pressure on the surface of a supersonic aircraft, which would minimize any recirculation problems. As indicated in [38], challenges remain regarding the cost and weight of such a system, and engine cycle penalties associated with the required steady source of bleed air. However, a combination of two or more flow control concepts could minimize such installation penalties. For example, utilizing the flow removed from aspirated compressor blades [36,37] as a blowing source for microblowing elsewhere in an aircraft, is an attractive combination of two new technologies [38].

\section{Concluding Remarks}

Experimental results of the direct measurement of turbulent skin friction were presented herein to assess a new technology called the Microblowing Technique (MBT). A consistent skin friction reduction of more than $50 \%$ in subsonic flow and more than $80 \%$ in supersonic flow was demonstrated. A challenge that remains is how to obtain the blowing air resources with minimal system penalties. Therefore, large-scale experiments, including using MBT in combination with other suction boundary layer flow control methods, are needed to further evaluate this technology and push it forward for real-world applications. 


\section{Acknowledgements}

The author conducted many experiments between 1995 until 2002. The financial support given by NASA Glenn (the Director's Discretionary Fund, the Green Engine Project, the Supersonic Quiet Engine program, and the Propulsion Base Program), are gratefully acknowledged. The author also would like to acknowledge the Branch Chiefs, Thomas Biesiadny, and Dennis Huff, for their support and encouragement from the early stages of the development. Many authors have contributed to this article: Greg Tillman of United Technologies Research Center; Prof. Tom Shih, Prof. M.K. Chyu, and Mr. Y.L. Lin of Carnegie Mellon University; Prof. Suresh Menon and H. Feiz of Georgia Institute of Technology; Gerard Welch, Louis Larosiliere and Jerry Wood of NASA Glenn. Without the effort of these authors, the MBT would still be in the infancy stage. The author also would like to express sincere thanks to Robert Voisinet of the Naval Surface Weapons Center for providing the force balance used for the experiments. The author would like to thank Charles Parente of Northrop Grumman for supplying numerous porous plates for testing.

Since no one can predict the outcome of the experiments, the effort given by the following individuals to make experiments successful are greatly appreciated: Tony Herrmann, Gwynn Severt, Kurt Loos, Joyel Kerl, Scott Panko, Carlos Gomez, and Wayne Stopack.

\section{References}

[1] Joslin RD. Overview of laminar flow control. NASATP-1998-208705, 1998.

[2] Lord WK, Zysman SH, Tillman TG, Johnson WA. Laminar flow control experiment on a large-scale nacelle model. Pratt \& Whitney Report PWA 6420-55, 1995.

[3] Tillman TG. An experimental study of two-dimensional surface roughness and simulated engine fan noise on nacelle laminar flow control. UTRC Report R97-4.100.0021, 1997.

[4] Wie YS, Collier FS, Jr., Wagner RD. Application of laminar flow control to high-bypass-ratio turbofan engine nacelles. SAE Paper 912114, 1991. 
[5] Barry B, Parke SJ, Bown NW, Riedel H, Sitzmann M. The flight testing of natural and hybrid laminar flow nacelles. ASME Paper 94-GT-408, 1994.

[6] Runyan LJ, Bielak GW, Behbehani RA, Chen AW, Rozendaal RA. The 757 NLF glove flight test results. In: Hefner J, Sabo F, editors. Proceedings of the Research in Natural Laminar Flow and Laminar-Flow Control, NASA CP-2487, pt. 3, 1990, p. 795-818.

[7] Nieuwstadt FTM, Wolthers W, Leijdens H, Prasad KK, Schwarzvanmanen A. The reduction of skin friction by riblets under the influence of an adverse pressure-gradient. Exp Fluids 1993;15(1):17-26.

[8] Debisschop JR, Nieuwstadt FTM. Turbulent boundary layer in an adverse pressure gradient: Effectiveness of riblets. AIAA J 1996; 34(5):932-937.

[9] Lynch FT, Klinge MD. Some practical aspects of viscous drag reduction concepts. SAE Paper 912129, 1991.

[10] Jeromin LOF. The status of research in turbulent boundary layers with fluid injection. In: Kuchemann D, editor. Progress in Aeronautical Sciences, Pergamon Press, 1966, p. 65-189.

[11] Voisinet RLP. Influence of roughness and blowing on compressible turbulent boundary layer flow; skin friction drag; final report. NSWC/TR-79-153, 1979.

[12] Healzer JM, Moffat RJ, Kays WM. The turbulent boundary layer on a rough, porous plate: Experimental heat transfer with uniform blowing. SU-HMT-18, 1974. 
[13] Dahm TJ, Kendall RM, Mendenhall MR, Rubesin MW. Mass, momentum, and heat transfer within a turbulent boundary layer with foreign gas mass transfer at the surface. Part $1-$ Constant fluid properties final report. REPT.-111, 1964.

[14] Goodwin BM. The transpired turbulent boundary layer with zero pressure gradient. Doctor of Science Thesis, Massachusetts Institute of Technology, 1961.

[15] Simpson RL, Moffat RJ, Kays WM. The turbulent boundary layer on a porous plate: experimental skin friction with variable injection and suction. Int J Heat Mass Transfer 1969;12(7):771-789.

[16] Dershin H, Gallaher WH, Leonard CA. Direct measurement of skin friction on a porous flat plate with mass injection. AIAA J 1967;5:1934-1939.

[17] Simpson RL. Characteristics of turbulent boundary layers at low Reynolds numbers with and without transpiration. J Fluid Mech 1970;42(4):769-802.

[18] Jeromin LOF. An experimental investigation of the compressible turbulent boundary layer with air injection. ARC Reports and Memoranda No. 3526, Aeronautical Research Council, London, England, 1968.

[19] Wilkinson SP. Influence of wall permeability on turbulent boundary-layer properties. AIAA Paper 83-0294, 1983.

[20] Hwang DP. Skin friction reduction by micro-blowing technique. U.S. Patent 5,803,410, Dec. 1998.

[21] Beltran LR, Delroso RL, Delrosario R. Advanced nozzle and engine components test facility. NASA TM-103684, 1992. 
[22] Lin YL, Chyu MK, Shih Tl-P, Willis BP, Hwang DP. Skin-friction reduction through micro blowing. AIAA Paper 98-0359, 1998.

[23] Hwang DP. A proof of concept experiment for reducing skin friction by using a micro-blowing technique. NASA TM-107315, 1996.

[24] Hwang DP, Biesiadny TJ. Experimental evaluation of the penalty associated with micro-blowing for reducing skin friction. NASA TM-113174, 1997.

[25] Tillman TG. Drag reduction on a large-scale nacelle using micro-porous blowing. UTRC Report R97-4.910.0001, 1997.

[26] Tillman TG, Hwang DP. Drag reduction on a large-scale nacelle using a micro-blowing technique. AIAA Paper 99-0130, 1999.

[27] Hwang DP, An experimental study of turbulent skin friction reduction in supersonic flow using a microblowing technique. AIAA-2000-545, 2000.

[28] Welch GE, Larosiliere LM, Hwang DP, Wood JR. Effectiveness of micro-blowing technique in adverse pressure gradients. NASATM-2001-210690, 2001.

[29] Hwang DP. Experimental study of characteristics of micro-hole porous skins for turbulent skin friction reduction. In: Procceedings of the 23rd International Congress of Aeronautical Sciences, Toronto, Canada, 2002, p. 2101.1-2101.7.

[30] Thomas J,, Anderson WK, Krist, ST. Navier-Stokes computations of vertical flows over low-aspectratio wings. AIAA J 1990;28:205-212. 
[31] Rumsey CL, Vatsa VN. A comparison of the predictive capabilities of several turbulence models using upwind and central-difference computer codes. AIAA-93-0192, 1993.

[32] Menon S. Large-eddy/lattice Boltzmann simulations of micro-blowing strategies for subsonic and supersonic drag control. NASA/CR-2003-212196, 2003.

[33] Feiz H, Menon S. LES of multiple jets in crossflow using a coupled lattice Boltzmann-finite volume solver. AIAA Paper 2003-5206, 2003.

[34] Menon S, Feiz, H. Blowing simulations using a coupled finite-volume lattice-Boltzman LES approach. CCL Report 2003-010, 2003.

[35] Feiz H, Soo J, and Menon S. LES of turbulent jet flows using the lattice Boltzmann approach. AIAA-2003-780, 2003.

[36] Kerrebrock J, Reijnen DP, Ziminsky WS, Smilg, LM. Aspirated compressors. 97-GT-525, 1997.

[37] Kerrebrock JL, Drela M, Merchant AA, Schuler BJ. Family of designs for aspirated compressors. 98-GT-196, 1998.

[38] Lord WK, MacMartin, DG, Tillman TG. Flow Control Opportunities in Gas Turbine Engines. AIAA $2000-2234,2000$. 
Fig. 1. Microblowing Technique (MBT) skin.

Fig. 2. Shape of laser-drilled holes.

Fig. 3. Force balance used to measure skin friction.

Fig. 4. New two components force balance.

Fig. 5. Rectangular wind tunnel.

Fig. 6. Unblown skin friction ratio.

Fig. 7. Skin friction ratio of NASA PN2 at exhaust pressure of $0.24 \mathrm{~atm}$.

Fig. 8. Static pressure distribution along the wind tunnel.

Fig. 9. Skin friction ratio at $\mathrm{Mach}=0.3$.

Fig. 10. Test model for measuring total drag.

Fig. 11. Experimental setup.

Fig. 12. Drag ratio of GAC1897.

Fig. 13. Unblown drag ratio.

Fig. 14. UTRC nacelle test model.

Fig. 15. Wind tunnel wall axial static pressure distributions.

Fig. 16. Skin friction drag ratio for zero pressure gradient case.

Fig. 17. Skin friction drag ratio for mild adverse pressure gradient case.

Fig. 18. Skin friction drag ratio for strong adverse pressure gradient case.

Fig. 19. Supersonic tunnel and balance.

Fig. 20. Wall static pressure along supersonic duct.

Fig. 21. Skin friction ratio in supersonic flow at Mach $=1.9$.

Fig. 22. Schematic diagram of two-dimensional diffuser (top view) showing strut test model and traversing total pressure rake for wake surveys.

Fig. 23. Skin friction ratio in adverse pressure gradients for PN23 porous plate.

Fig. 24. Search for minimum value of skin friction ratio with respect to hole diameter Reynolds number.

Fig. 25. Search of minimum value of skin friction ratio with respect to aspect ratio.

Fig. 26. Search for minimum value of skin friction ratio with respect to porosity.

Fig. 27. Schematic of problem studied. 
Fig. 28. Grid system used in the region about the microholes.

Fig. 29. Velocity vector field and stream lines near the plate surface about the third microhole.

Fig. 30. Spanwise-average normalized shear stress with holes included.

Fig. 31. Spanwise-averaged normalized shear stress with holes excluded.

Fig. 32. Geometry and grid configuration for multihole simulation (every fifth grid is shown).

Fig. 33. $U^{+}$velocity profile in the wall coordinate $Y^{+}$.

Fig. 34. Skin friction ratios along the plate for different blowing fraction. 
Table I.-Specifications of Test Plates for Subsonic Test

\begin{tabular}{lccccc}
\hline $\begin{array}{c}\text { Plate } \\
\text { name }\end{array}$ & $\begin{array}{c}\text { Hole cross- } \\
\text { sectional shape } \\
\text { (side view) }\end{array}$ & $\begin{array}{c}\text { Hole } \\
\text { diameter, } D, \\
\mathrm{~mm}\end{array}$ & $\begin{array}{c}\text { Thickness of } \\
\text { plate, } T, \\
\mathrm{~mm}\end{array}$ & $\begin{array}{c}\text { Porosity, } \\
\%\end{array}$ & $\begin{array}{c}\text { Aspect ratio, } \\
T / D\end{array}$ \\
\hline NASA PN2 & Straight & 0.165 & 1.02 & 23 & 6.2 \\
\hline NASA PN3 & Straight & 0.254 & 1.02 & 23 & 4 \\
\hline GAC 2004 & Conical & 0.381 & 0.787 & 21 & 2.1 \\
GAC 2003 & Conical & 0.152 & 0.305 & 21 & 2 \\
\hline GAC 2005 & Conical & 0.076 & 0.152 & 23 & 2 \\
\hline GAC 2002 & Conical & 0.229 & 0.394 & 31 & 1.7 \\
\hline GAC 1897 & Hourglass & 0.06 & 0.305 & $50^{2}$ & 5.1 \\
\hline a
\end{tabular}

${ }^{a}$ The porosity is $4 \%$ based on the small neck area. 
Table II.-Specifications of Test Plates for Pressure Drag Test

\begin{tabular}{cccccc}
\hline $\begin{array}{c}\text { Plate } \\
\text { number }\end{array}$ & $\begin{array}{c}\text { Plate } \\
\text { name }\end{array}$ & $\begin{array}{c}\text { Hole shape } \\
\text { side view/top } \\
\text { view }\end{array}$ & $\begin{array}{c}\text { Hole size, } \\
\mathrm{mm}\end{array}$ & $\begin{array}{c}\text { Thickness, } \\
\mathrm{mm}\end{array}$ & Porosity \\
\hline 1 & Flat solid plate & N/A & N/A & 3.429 & N/A \\
\hline 2 & GAC1897 & Hourglass/circle & 0.06 & 0.305 & 50 \\
\hline 3 & GAC2038 & Conical/circle & 0.1 & 0.5 & 23 \\
\hline 4 & GAC2037 & Conical/circle & 0.08 & 0.5 & 14 \\
\hline 5 & GAC2036 & Conical/circle & 0.04 & 0.5 & 4 \\
\hline 6 & GAC2035 & Straight/slot & 0.04 by 0.45 & 0.5 & 20 \\
\hline 7 & GAC2035A & Straight/slot & 0.04 by 0.45 & 0.5 & 20 \\
\hline 8 & GAC 2034 & Straight/slot & 0.02 by 0.43 & 0.5 & 10 \\
\hline 9 & GAC2034A & Straight/slot & 0.02 by 0.43 & 0.5 & 10 \\
\hline 10 & GAC2033 $^{\mathrm{a}}$ & Straight/slot & 0.01 by 0.42 & 0.5 & 5 \\
\hline 11 & GAC2033A & Straight/slot & 0.01 by 0.42 & 0.5 & N/A \\
\hline 12 & Polyethylene & N/A & N/A & 6.35 & 1.1 \\
\hline 13 & LARC1 & Straight/irregular & 0.076 & 0.635 & \\
\hline
\end{tabular}

${ }^{\mathrm{a}}$ Long slot edge perpendicular to flow direction.

${ }^{b}$ Long slot edge along flow direction. 
Table III.-Specifications of Test Plates for Supersonic Test

\begin{tabular}{|c|c|c|c|c|c|}
\hline $\begin{array}{l}\text { Plate } \\
\text { name }\end{array}$ & $\begin{array}{c}\text { Porosity, } \\
\%\end{array}$ & $\begin{array}{c}\text { Hole } \\
\text { diameter, } D, \\
\mathrm{~mm}\end{array}$ & $\begin{array}{c}\text { Skin } \\
\text { thickness, } T, \\
\text { mm }\end{array}$ & $\begin{array}{l}\text { Aspect } \\
\text { ratio, } \\
T / D \\
\end{array}$ & Description/material \\
\hline Flat plate & & & & & Stainless steel \\
\hline GAC 1897 & 50 & 0.06 & 0.305 & 5.08 & $\begin{array}{c}\text { Northrop Grumman's plate, } \\
\text { nickel }\end{array}$ \\
\hline GAC 2054 & 4 & 0.13 & 0.23 & 1.769 & $\begin{array}{c}\text { Northrop Grumman's plate, } \\
\text { nickel }\end{array}$ \\
\hline PN 23 & 23 & 0.1651 & 1.016 & 6.15 & $\begin{array}{c}\text { Laser-drilled straight holes, } \\
\text { stainless steel }\end{array}$ \\
\hline PN4 & 23 & 0.1651 & 1.016 & 6.15 & $\begin{array}{c}5^{\circ} \text { angle holes, staggered, } \\
\text { stainless steel }\end{array}$ \\
\hline PN5 & 23 & 0.1651 & 1.016 & 6.15 & $\begin{array}{c}15^{\circ} \text { angle holes, staggered, } \\
\text { stainless steel }\end{array}$ \\
\hline PN6 & 23 & 0.1651 & 1.016 & 6.15 & $\begin{array}{c}5^{\circ} \text { angle holes, aligned, } \\
\text { stainless steel }\end{array}$ \\
\hline PN7 & 23 & 0.1651 & 1.016 & 6.15 & $\begin{array}{c}15^{\circ} \text { angle holes, aligned, } \\
\text { stainless steel }\end{array}$ \\
\hline
\end{tabular}


Table IV.-Test Plates for Parametric Study

\begin{tabular}{lclccc}
\hline $\begin{array}{c}\text { Plate } \\
\text { name }\end{array}$ & $\begin{array}{c}\text { Porosity, } \\
\%\end{array}$ & $\begin{array}{c}\text { Hole } \\
\text { diameter, } D, \\
\text { mm }\end{array}$ & $\begin{array}{c}\text { Skin } \\
\text { thickness, } T, \\
\text { mm }\end{array}$ & $\begin{array}{c}\text { Aspect } \\
\text { ratio } \\
T / D\end{array}$ & $\begin{array}{c}\text { Hole angle from } \\
\text { normal/pattern }\end{array}$ \\
\hline PN4 & 23 & 0.1651 & 1.016 & 6.15 & $5^{\circ}$, staggered \\
\hline PN5 & 23 & 0.1651 & 1.016 & 6.15 & $15^{\circ}$, staggered \\
\hline PN6 & 23 & 0.1651 & 1.016 & 6.15 & $5^{\circ}$, aligned \\
\hline PN7 & 23 & 0.1651 & 1.016 & 6.15 & $15^{\circ}$, aligned \\
\hline PN23 & 23 & 0.1651 & 1.016 & 6.15 & $0^{\circ}$, staggered \\
\hline PM1 & 13 & 0.1803 & 1.163 & 6.45 & $0^{\circ}$, staggered \\
\hline PP1 & 33 & 0.1803 & 1.163 & 6.45 & $0^{\circ}$, staggered \\
\hline DM1 & 23 & 0.066 & 0.432 & 6.54 & $0^{\circ}$, staggered \\
\hline DP1 & 23 & 0.29 & 1.864 & 6.44 & $0^{\circ}$, staggered \\
\hline ARM1 & 23 & 0.1803 & 0.574 & 3.23 & $0^{\circ}$, staggered \\
\hline ARP1 & 23 & 0.16 & 1.473 & 9.21 & $0^{\circ}$, staggered \\
\hline PP2 & 43 & 0.1803 & 1.163 & 6.45 & $0^{\circ}$, staggered \\
\hline DP2 & 23 & 0.523 & 3.353 & 6.41 & $0^{\circ}$, staggered \\
\hline
\end{tabular}

${ }^{a}$ PN23 is reference plate. It is the same as PN2 but made by different vendor. 

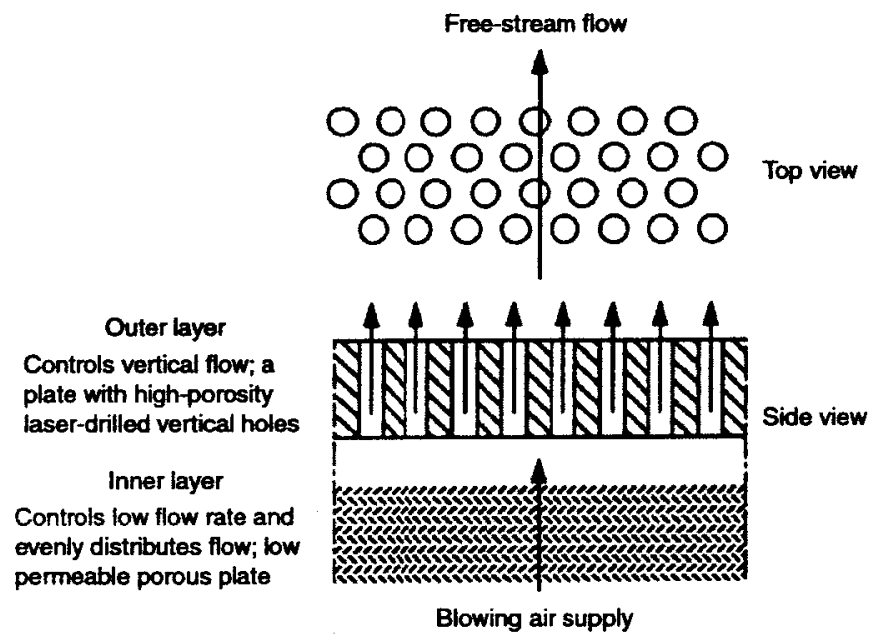

Fig 1 


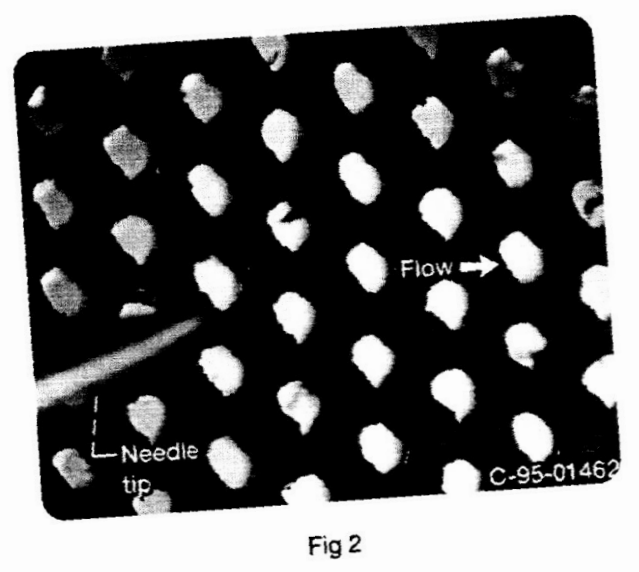




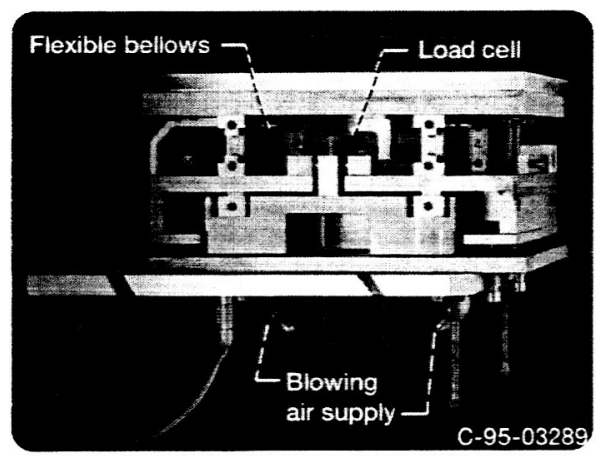

Fig 3 


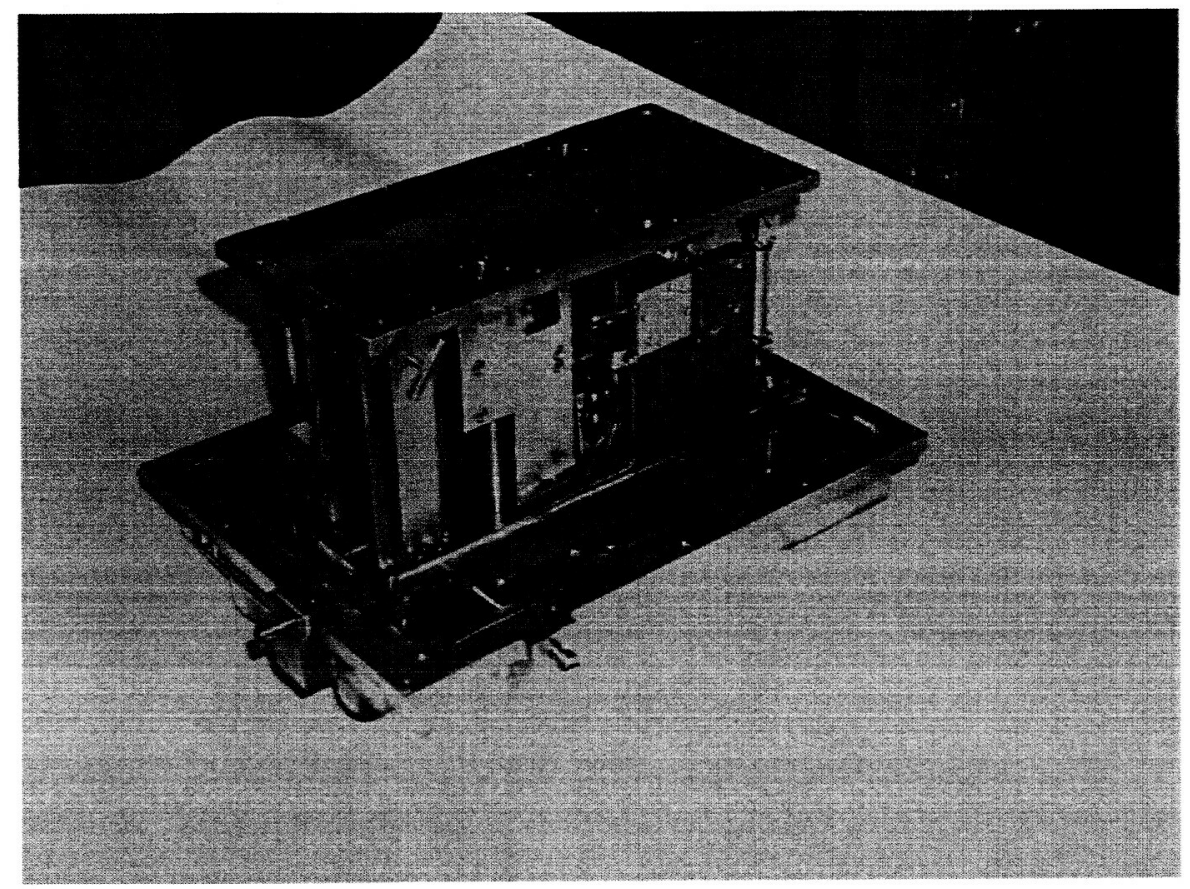

Fig 4 


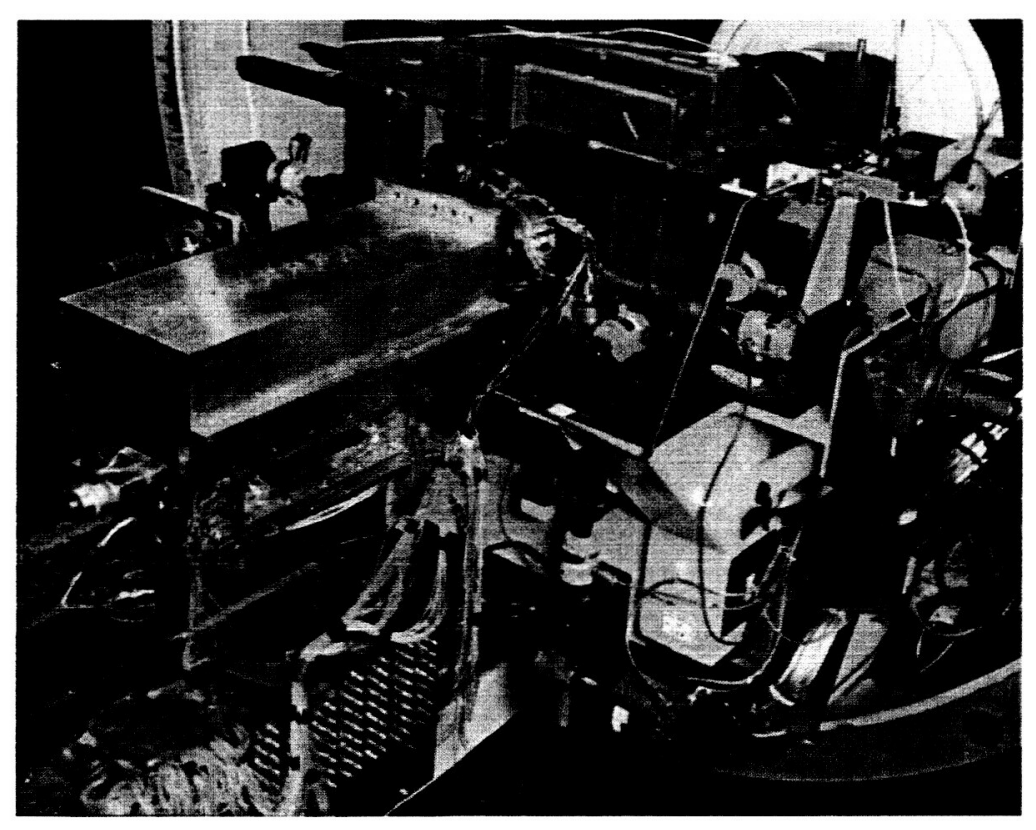

Fig 5 


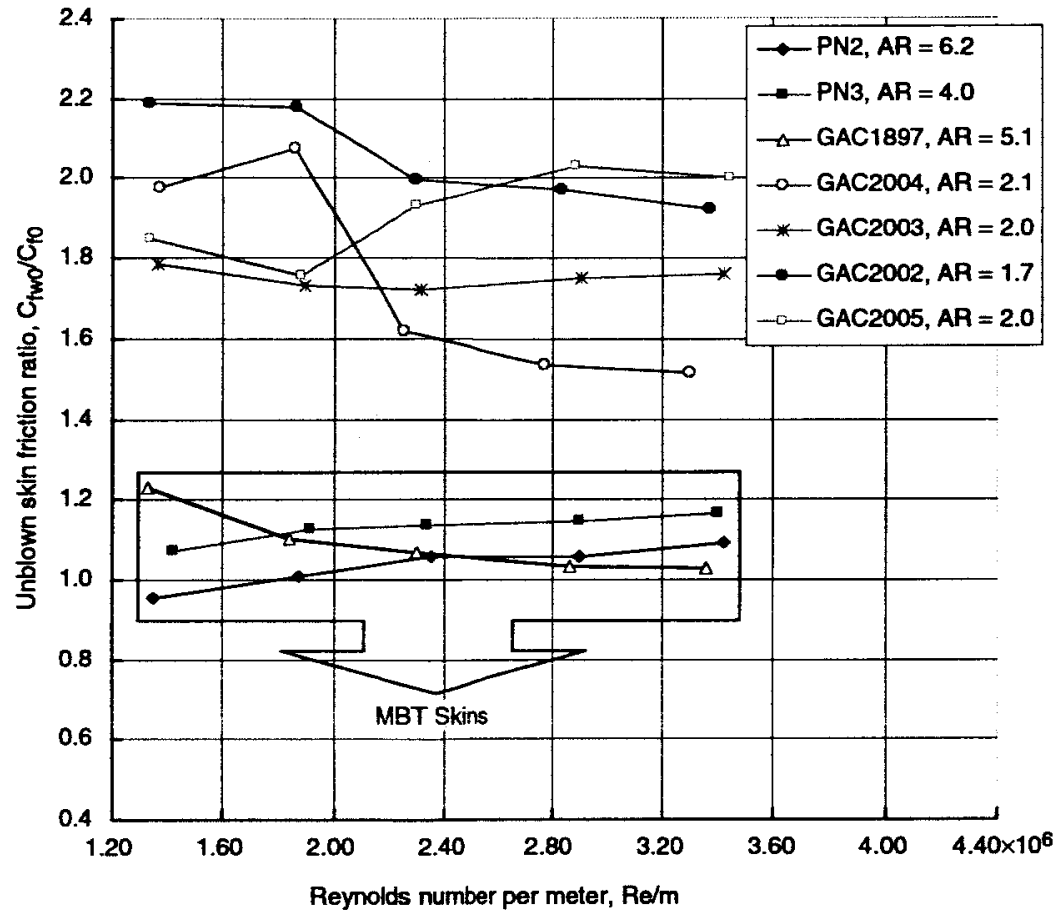

Fig 6 


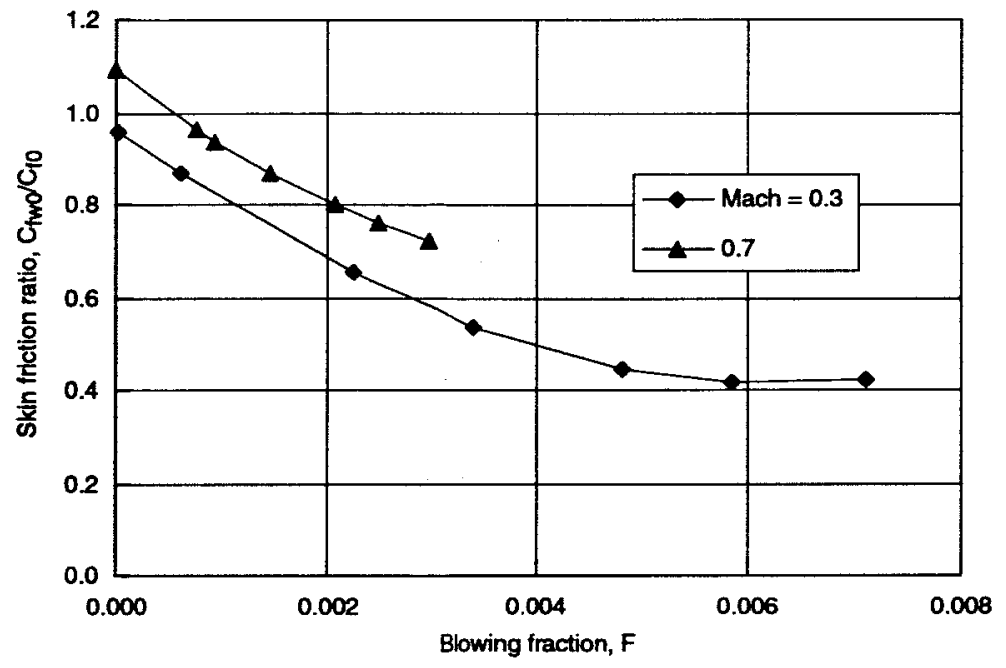

Fig 7 


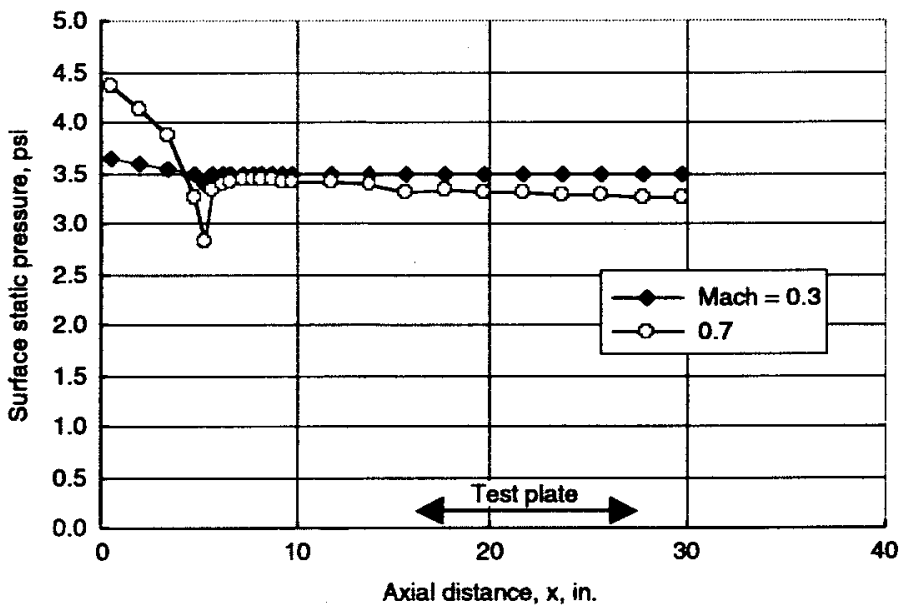

Fig 8 


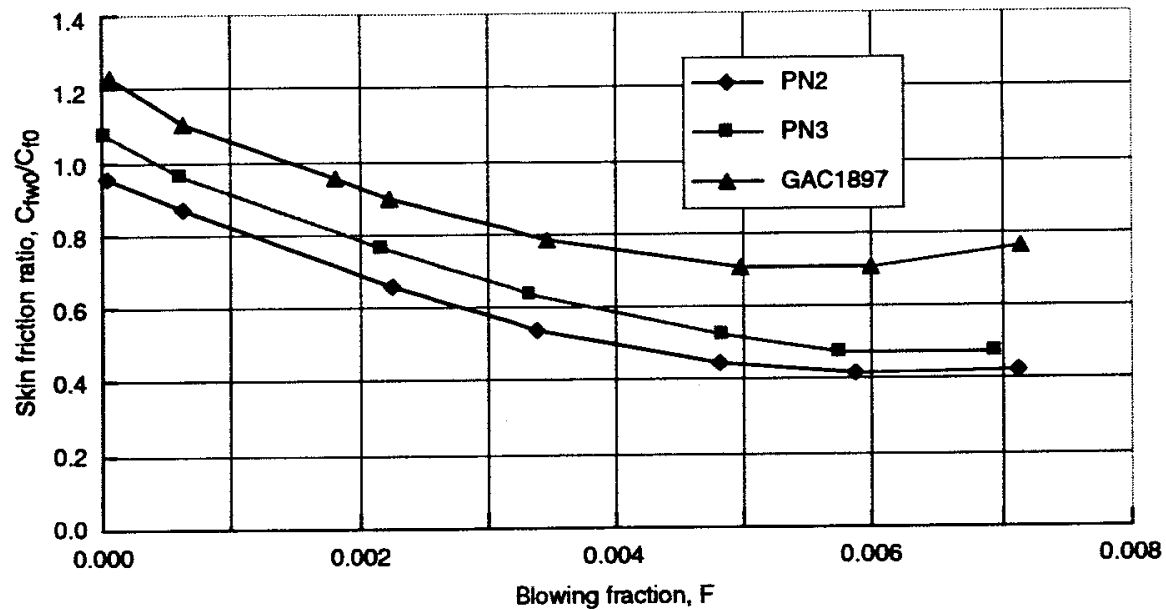

Fig 9 


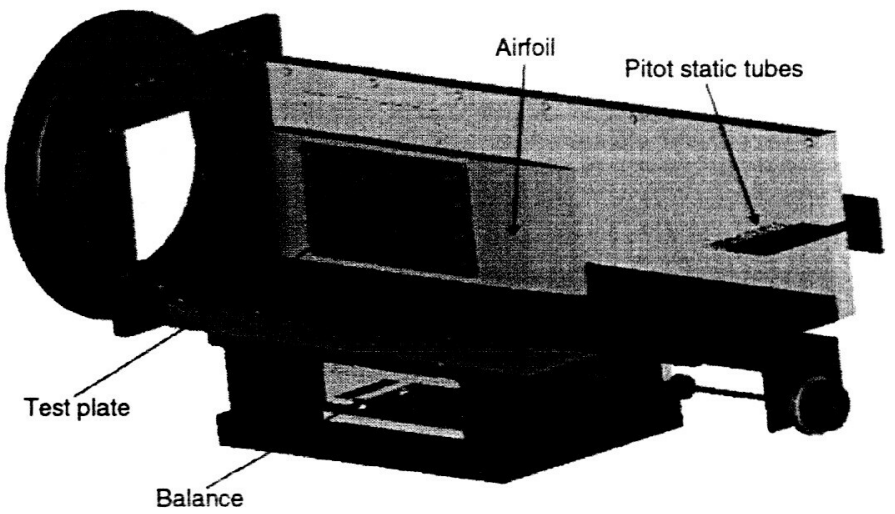

Fig 10 


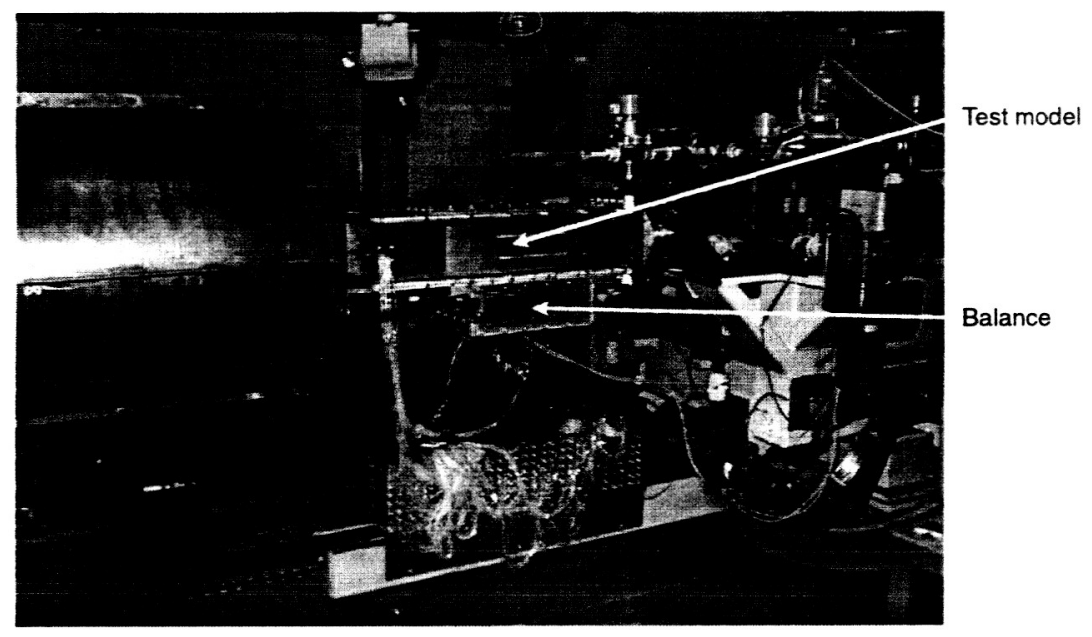

Fig 11 


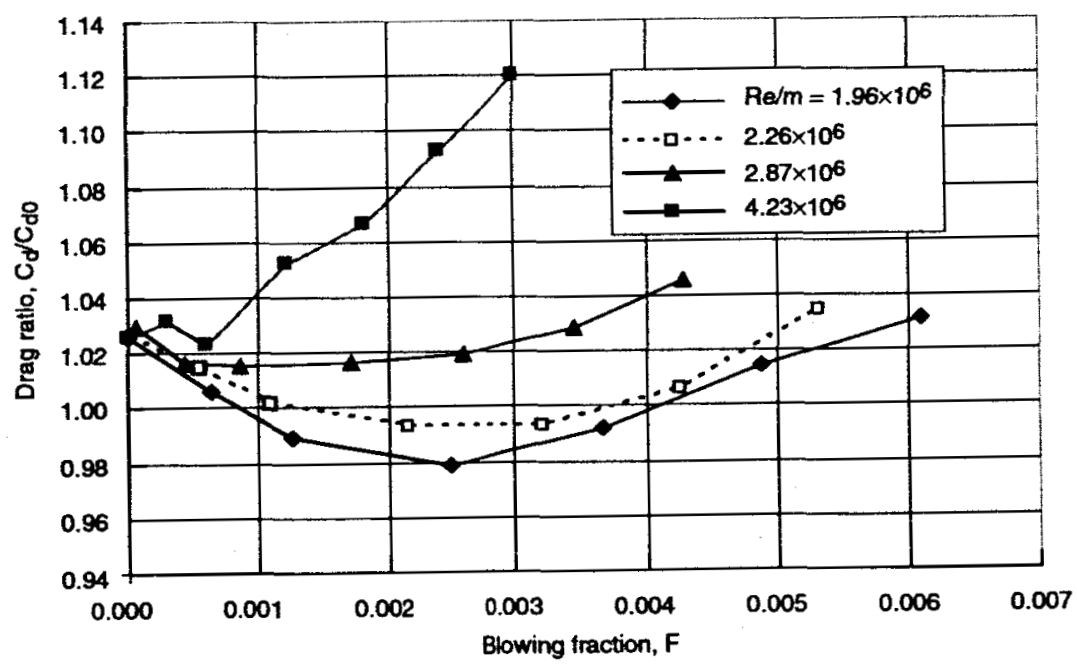

Fig 12 


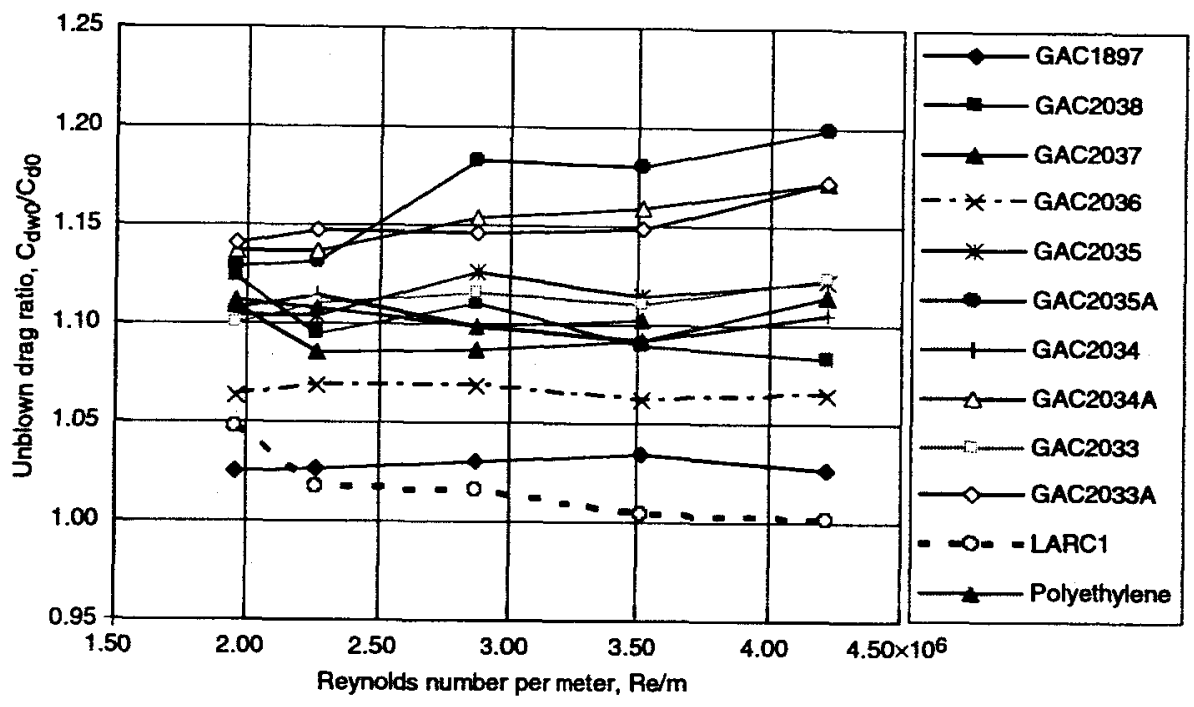

Fig 13 


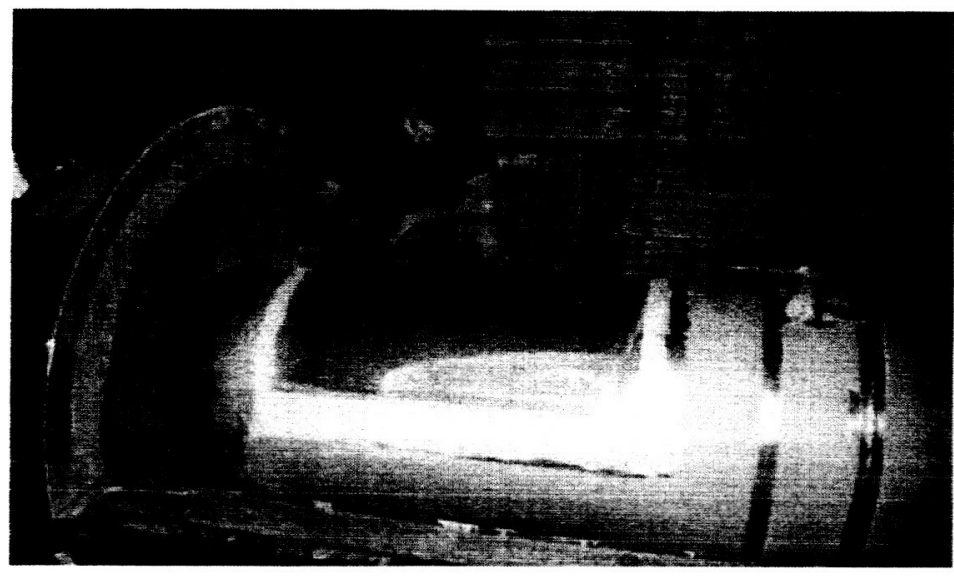

Fig 14 


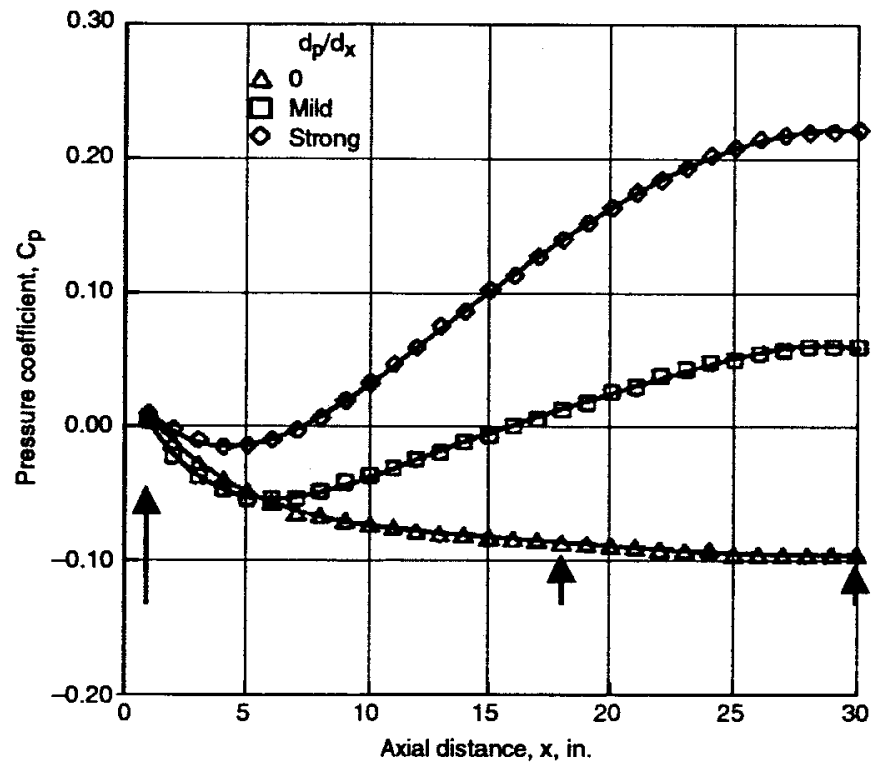

Fig 15 

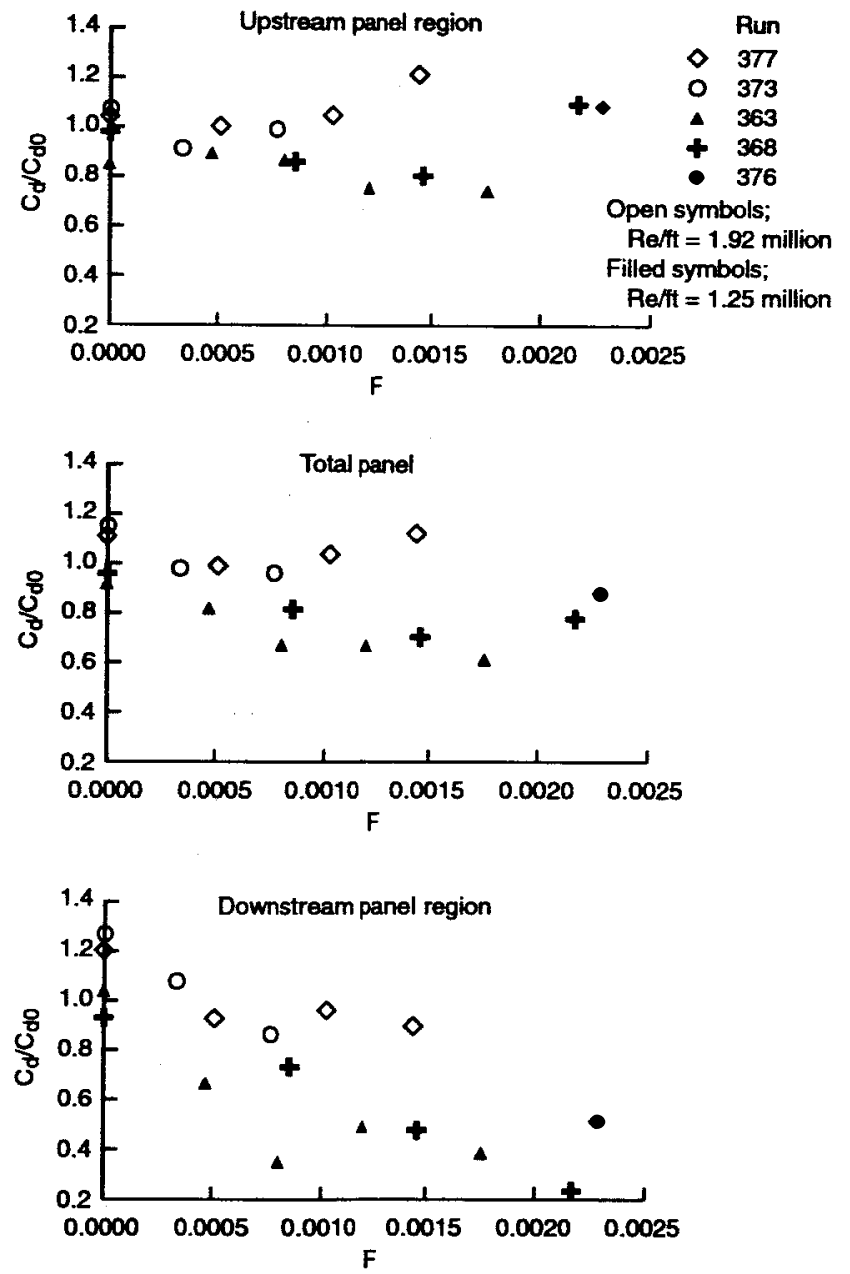

Fig 16 

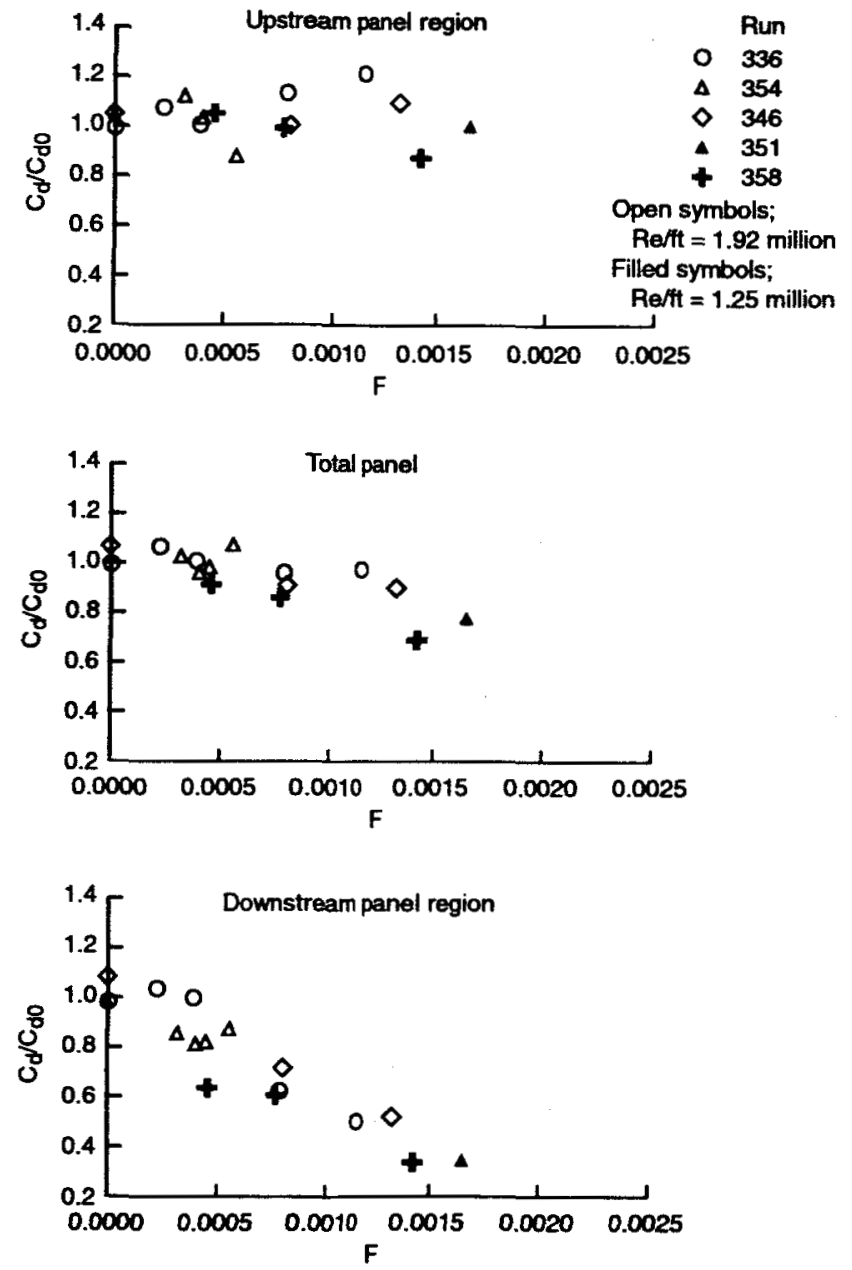

Fig 17 

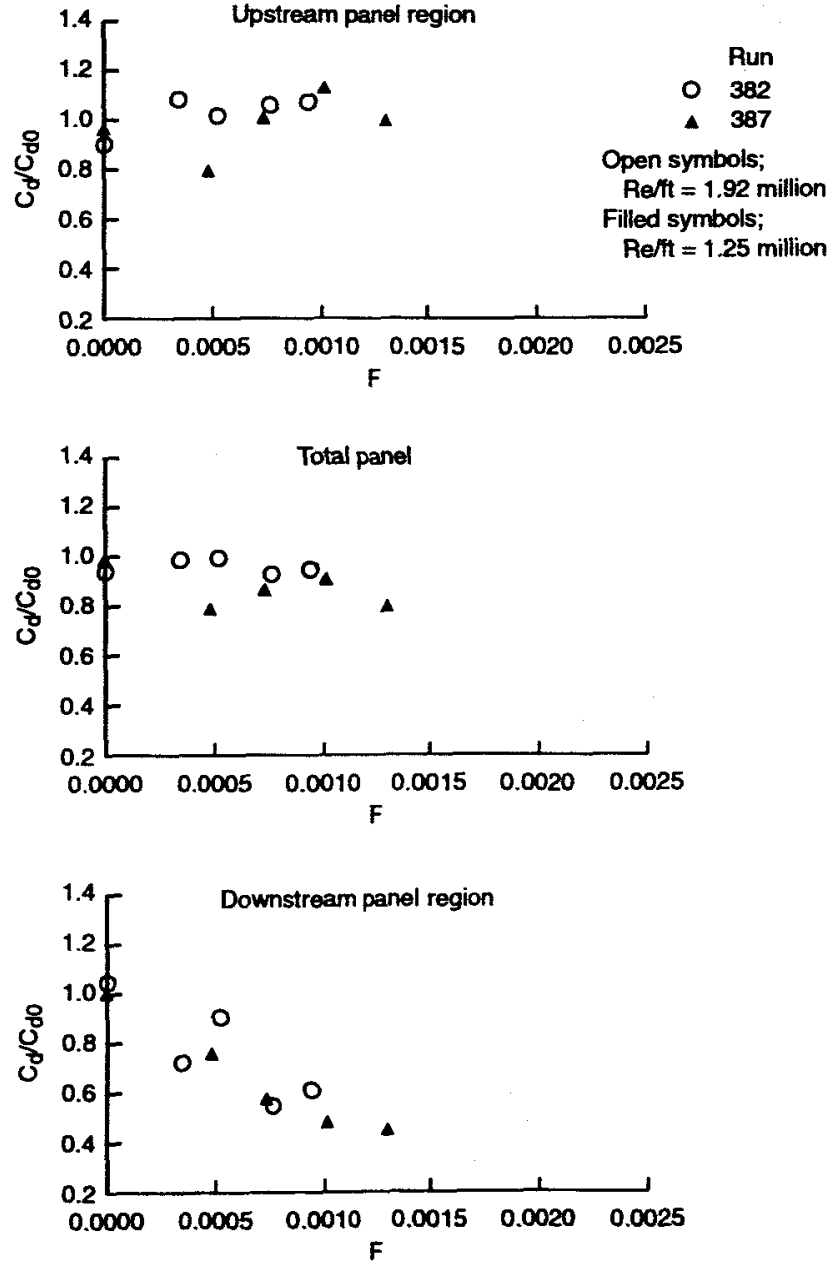

Fig 18 


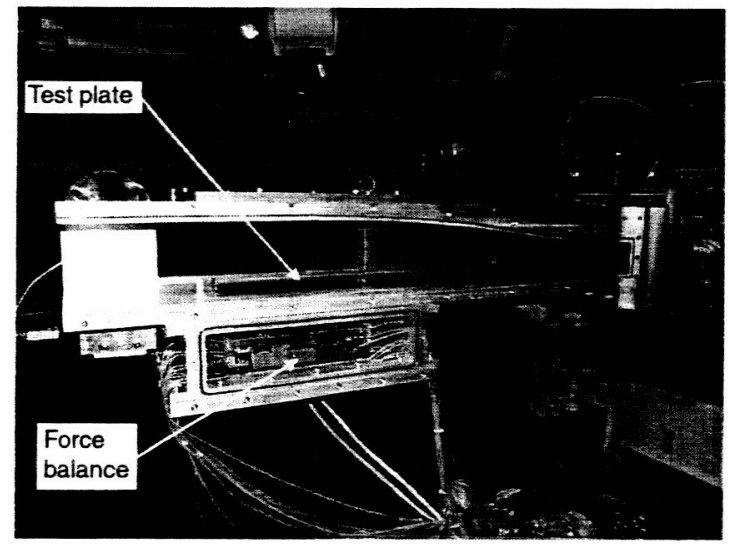

Fig 19 


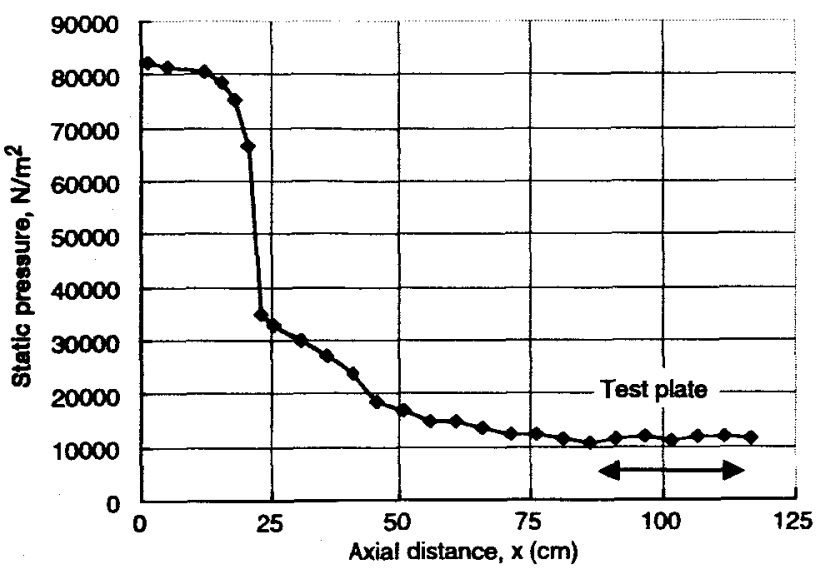

Fig 20 


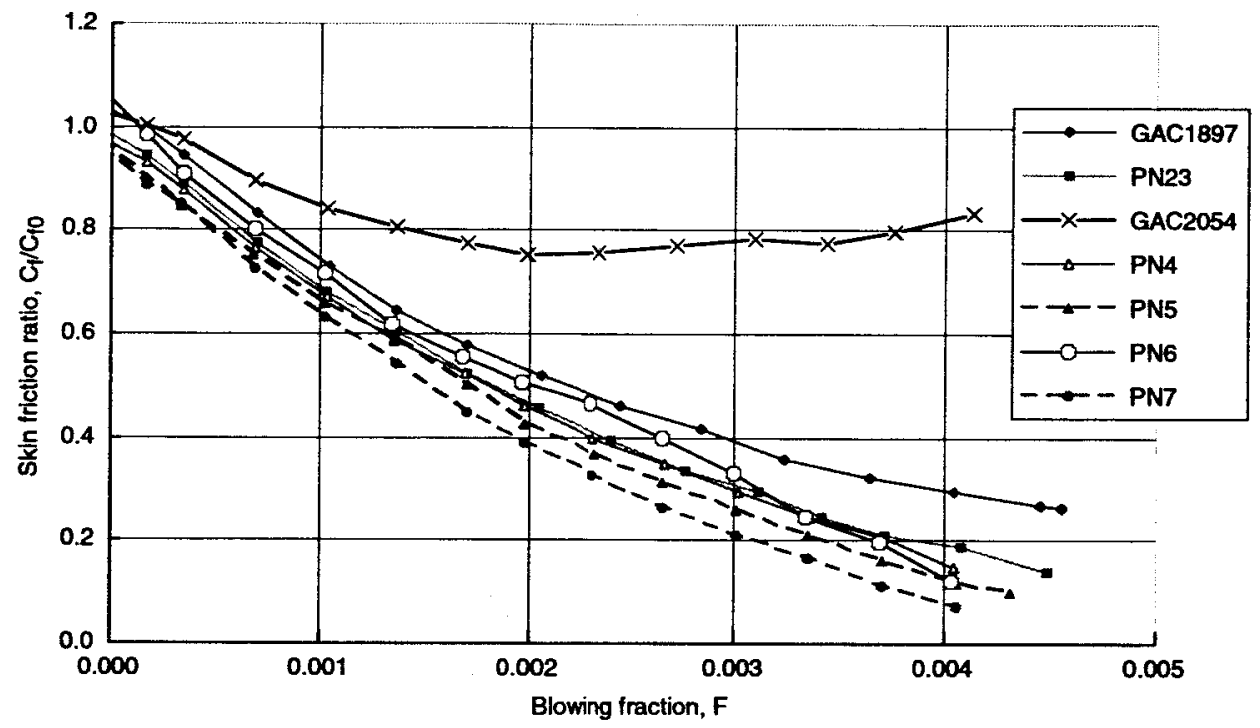

Fig 21 


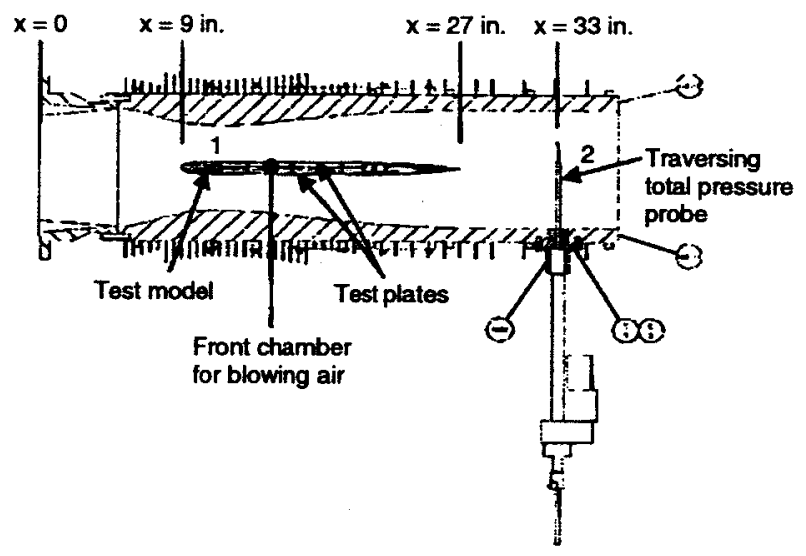

Fig 22 


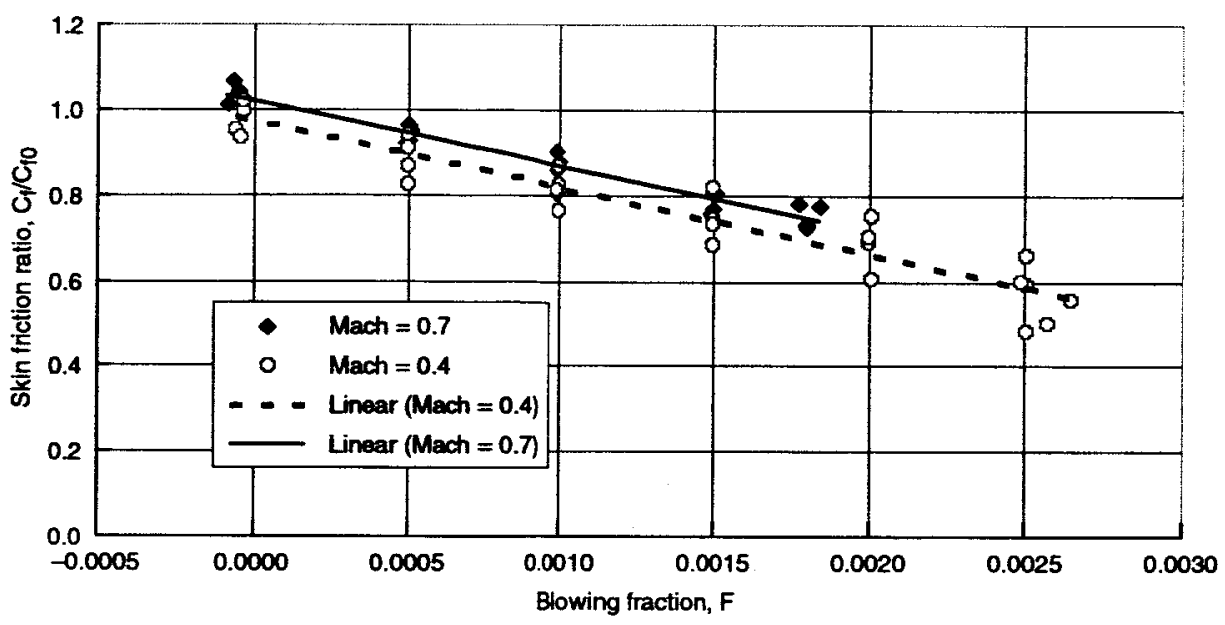

Fig 23 


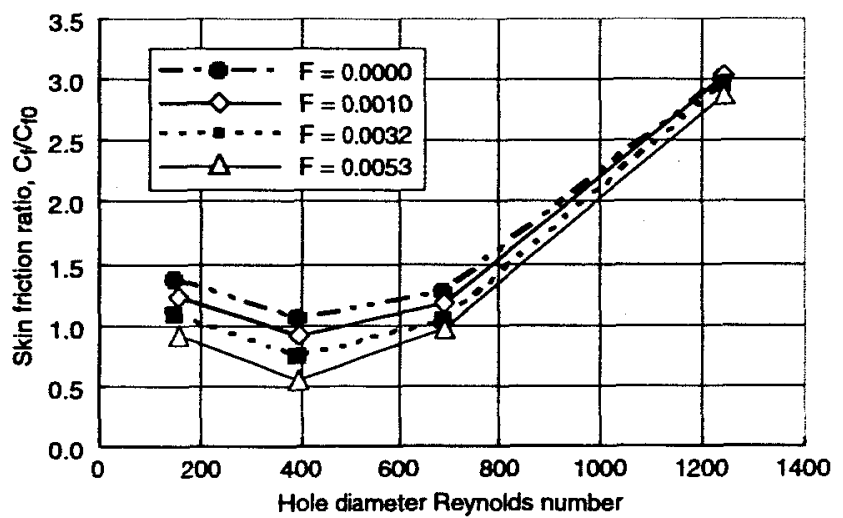

Fig 24 


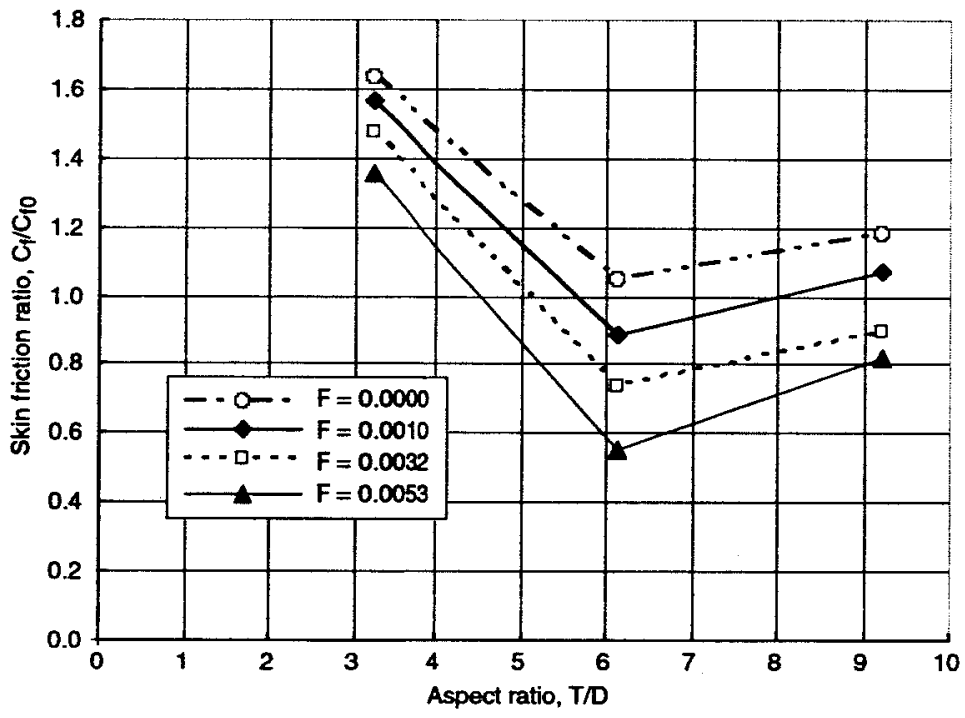

Fig 25 


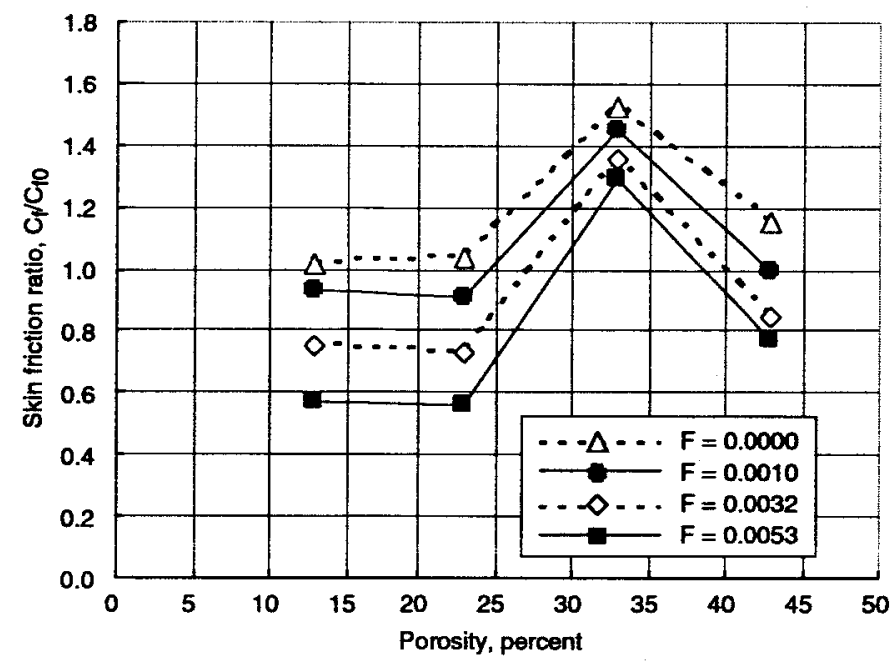

Fig 26 


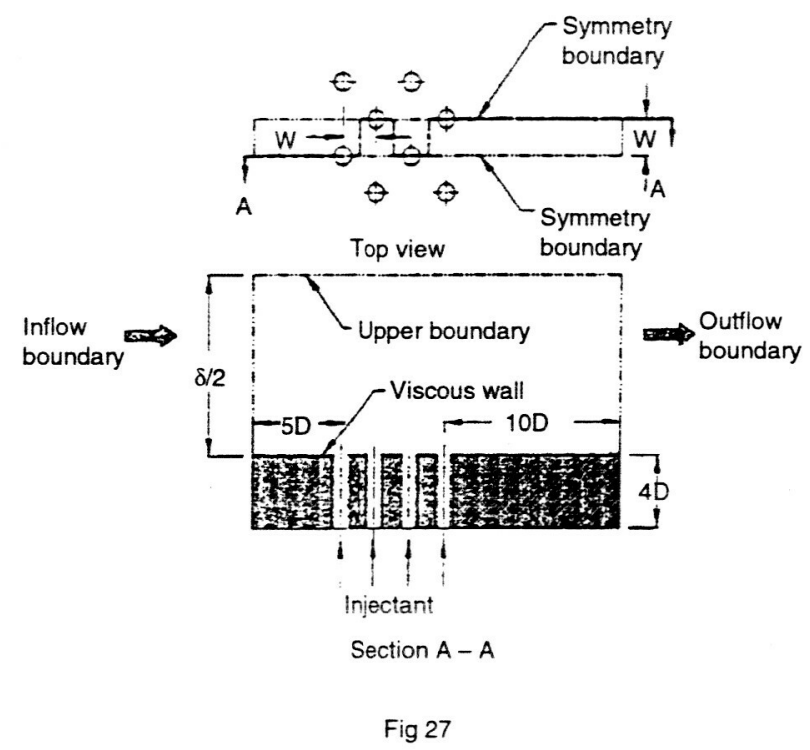




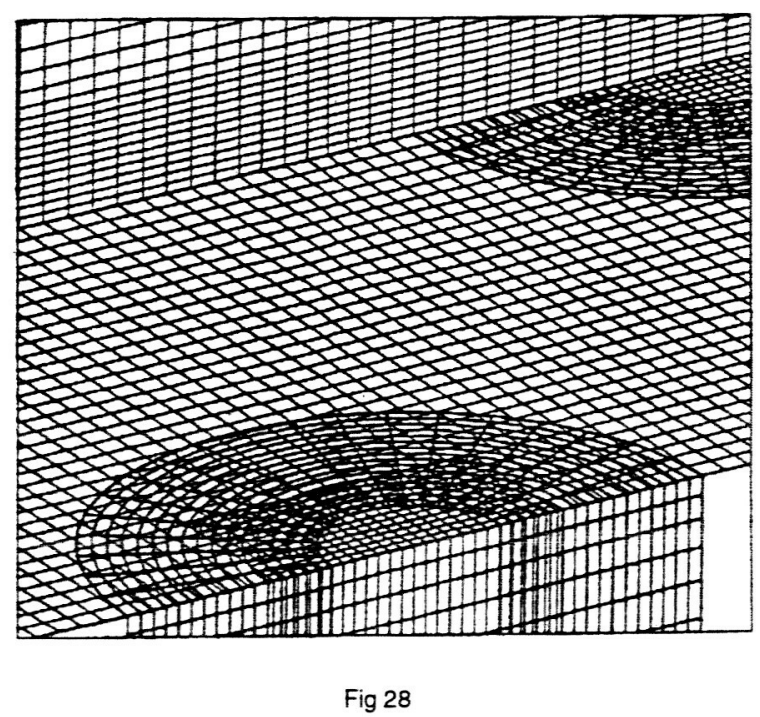



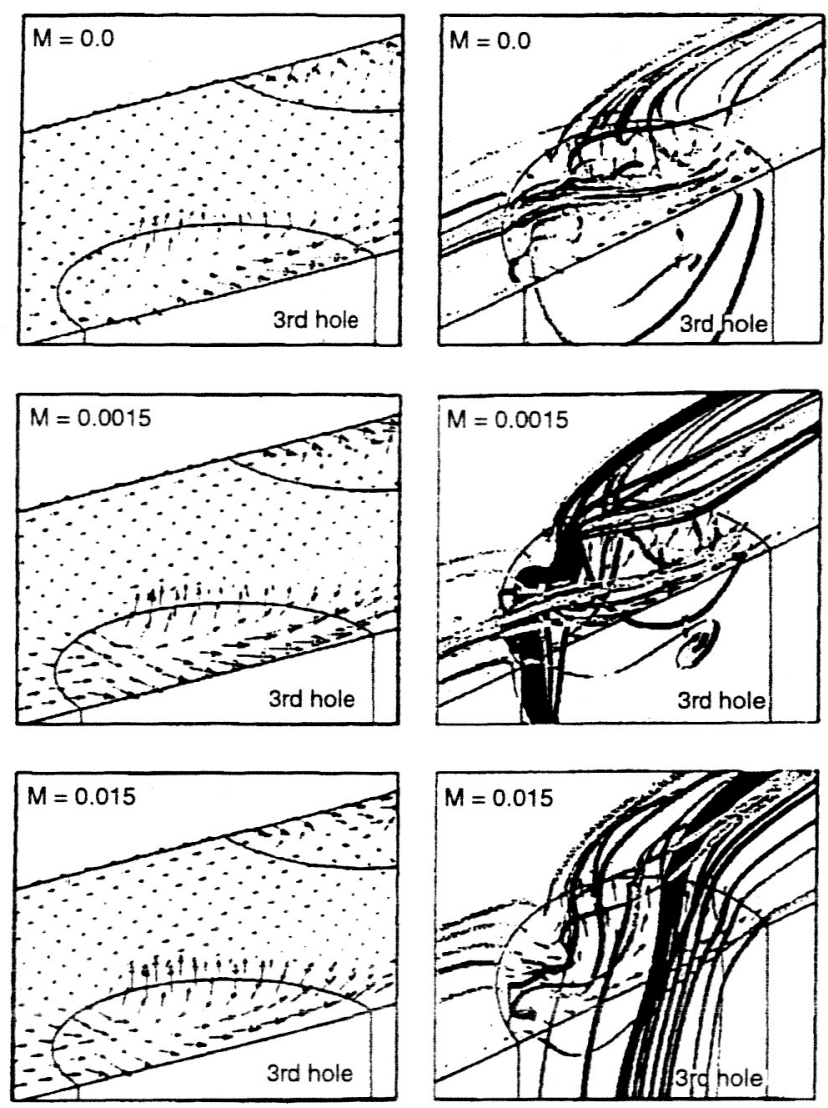

Fig 29 


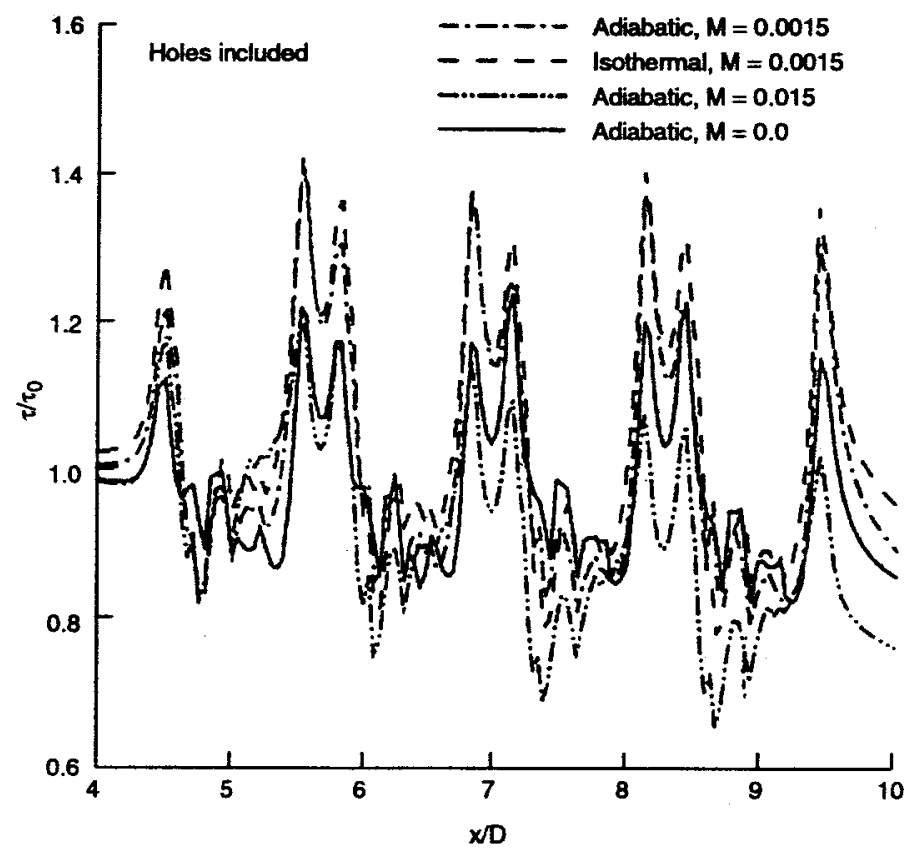

Fig 30 


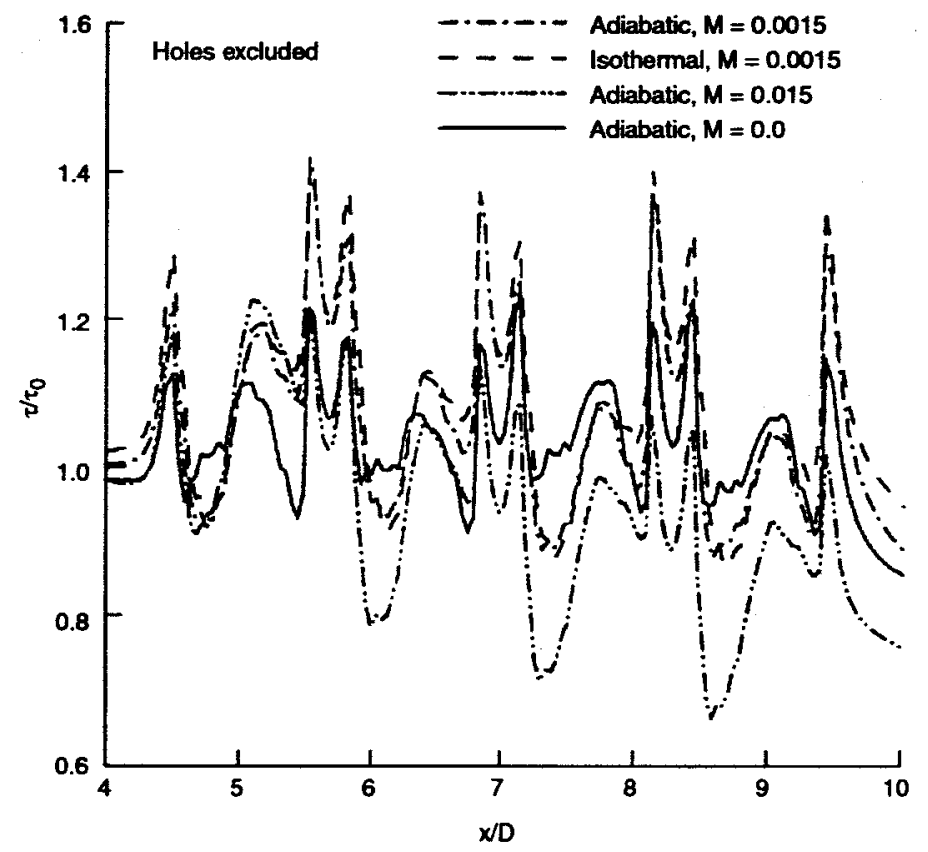

Fig 31 
Periodic
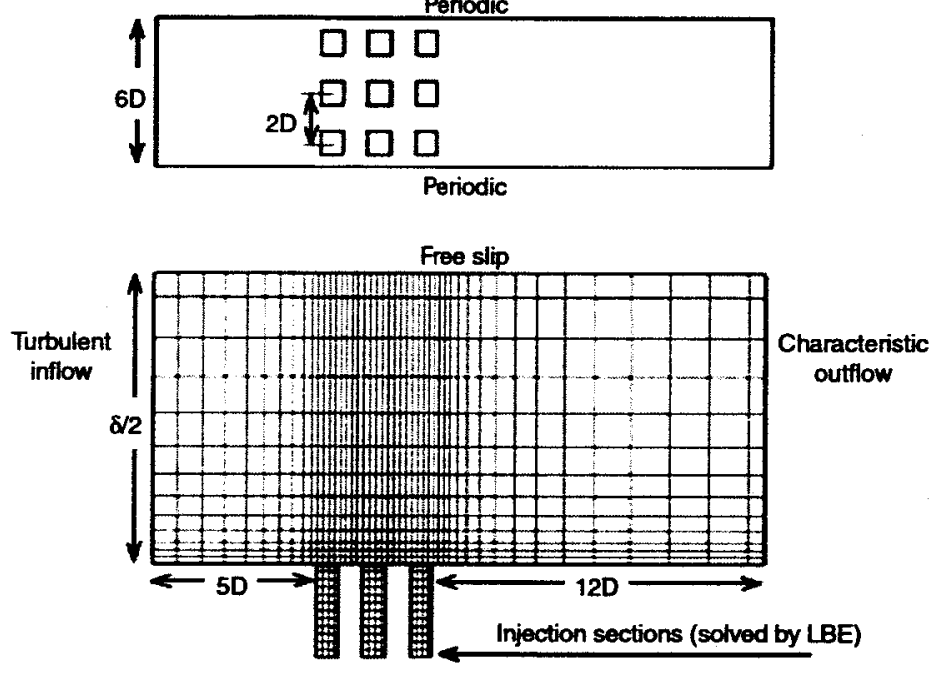

Fig 32 


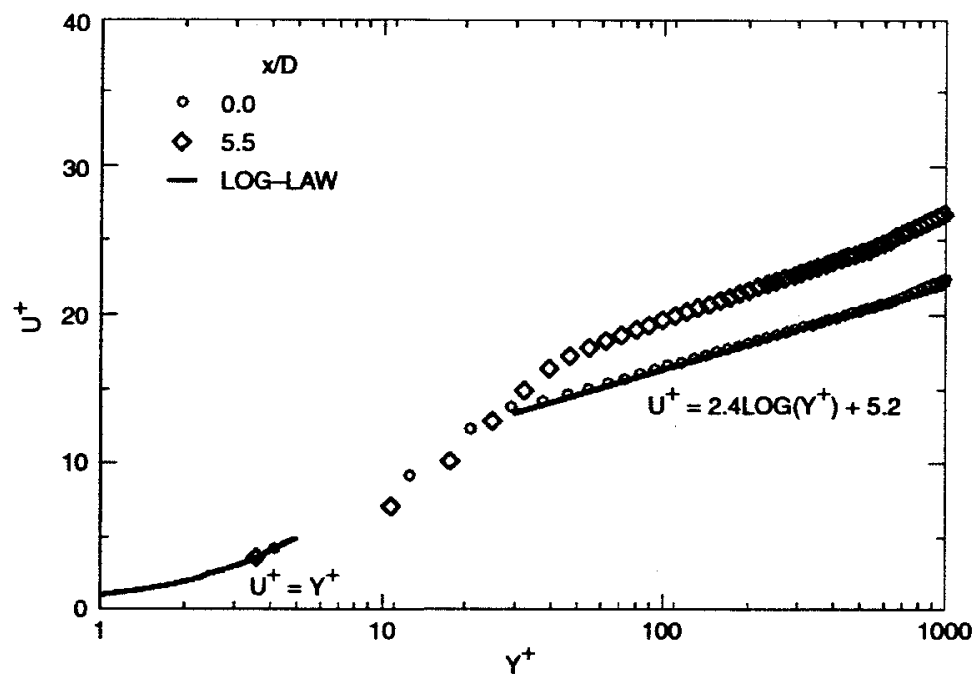

Fig 33 


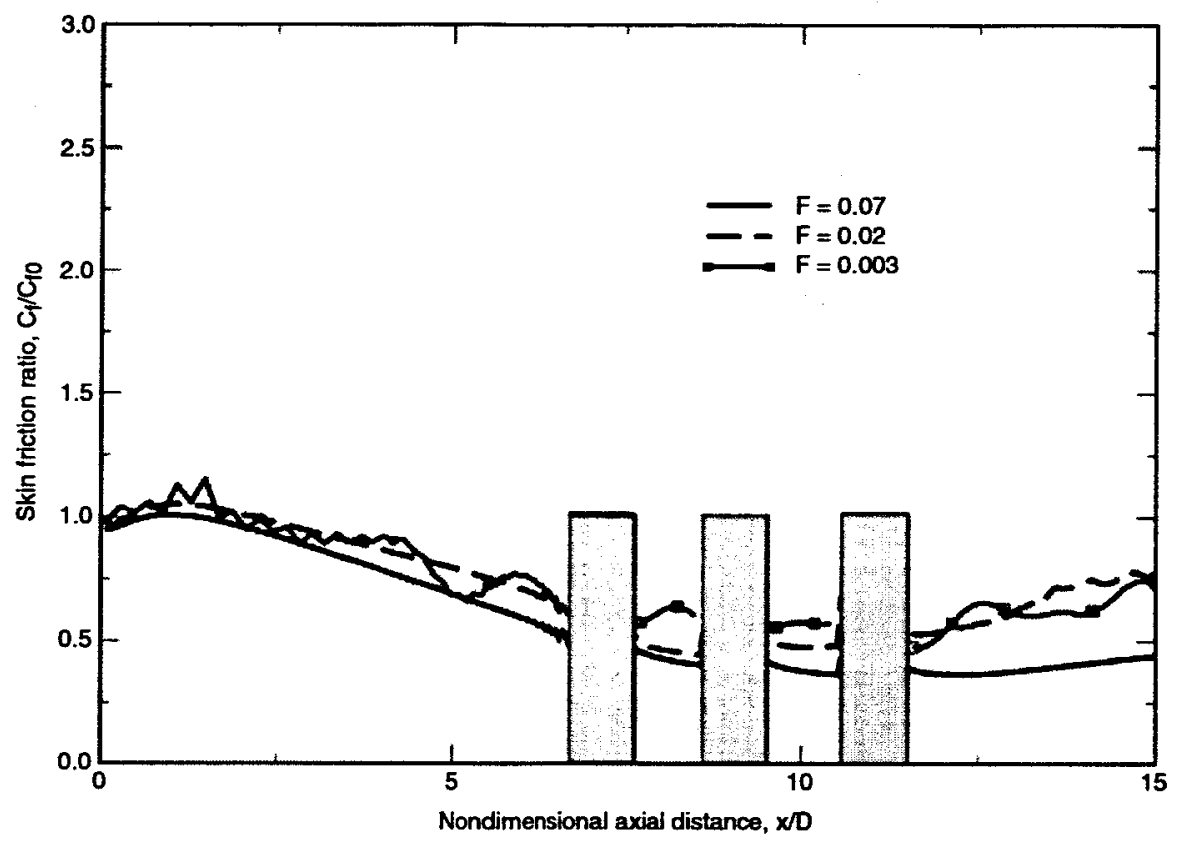

Fig 34 